\title{
RRESSURE DROP MEASUREMENTS IN THE TRANSITION \\ REGION FOR A CIRCULAR TUBE WITH A \\ SQUARE-EDGED ENTRANCE
}

\author{
By \\ JODY R. AUGUSTINE \\ Bachelor of science in Mechanical Engineering \\ The University of Southwestern Louisiana \\ Lafayette, Louisiana
}

1988

\author{
Submitted to the Faculty of the \\ Graduate college of the \\ oklahoma state University \\ in partial fulfillment of \\ the requirements for \\ the Degree of \\ MASTER OF SCIENCE \\ May, 1990
}


PRESSURE DROP MEASUREMENTS IN THE TRANSITION

REGION FOR A CIRCULAR TUBE WITH A

SQUARE-EDGED ENTRANCE

Thes is Approved:
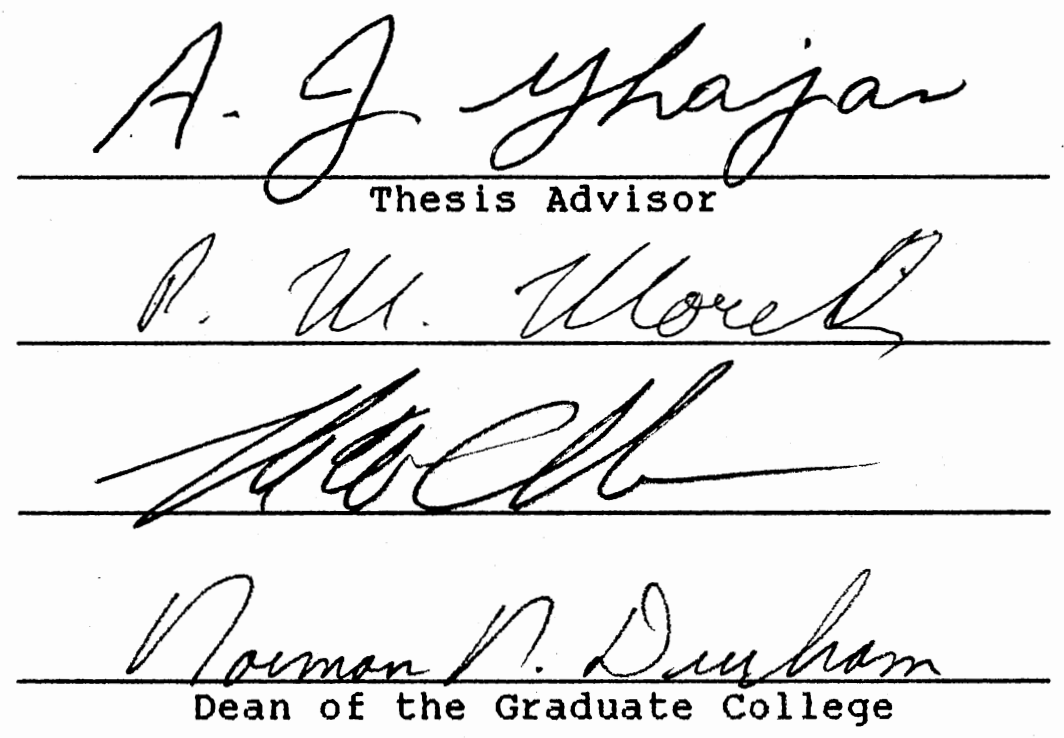


\section{ACKNOWLEDGMENTS}

I wish to thank my major advisor, Dr. A.J. Ghajar, for his patience and guidance throughout my entire graduate program. I also wish to express my gratitude toward my other committee members, Dr. F.W. Chambers and Dr. P.M. Moretti, for their helpful comments and discussion.

I would also like to thank the staff at the Mechanical Engineering North Labs for their helpeul assistance in all phases of the study.

I am grateful to the National science Foundation for supporting this study under grant number CBT-88103342.

Finally, I am especially indebted to my family and friends, for without their encouragement and understanding this study would have never been completed. 
TABLE OF CONTENTS

Chapter

Page

I . INTRODUCTION

Reasons for Research. . . . . . . . . 2

Objectives... . . . . . . . . . . . . 7

Method of Approach. . . . . . . . . 8

I . EXPERIMENTAL APPARATUS • . . . . . . . . . . . . 12

Description of the Equipment. . . . . . . 12

Test Section . . . . . . . . . . . 12

Equipment for Generating a Constant

Wall Heat Flux Condition . . . . . 14

Pressure Taps. . . . . . . . . . . 15

Pressure Tap Manifold. . . . . . . . . 17

Calming and Inlet Sections . . . . . . 19

Mixing Well. . . . . . . . . . . . . 21

Thermocouples. . . . . . . . . . . 21

Pumps . . . . . . . . . . . . . . . 23

Turbine Meters . . . . . . . . 24

Frequency Counter. . . . . . . . . 24

Heat Exchanger... . . . . . . . 25

Pressure Gauges and Manometer. . . . . 26

Reservoir. . . . . . . . . . . 26

Test Fluids. . . . . . . . . . . 27

Fluid Return Piping. . . . . . . . 27

Experimental Calibrations . . . . . . . . 28

ECD 5100 Data Logger . . . . . . . 28

Thermocouples. . . . . . . . . . . 28

Differential Pressure Gauges . . . . . 29

Turbine Meters . . . . . . . . . . 30

Calibration Runs... . . . . . . . 31

start-Up and operating Procedure. . . . . . 34

Some of the Problems Encountered. . . . . 38

Data Reduction. . . . . . . . . . . . 39

III. RESULTS AND DISCUSSION . . . . . . . . . . . . . 42

Moody Diagram . . . . . . . . . . . . . . 42

Transition Region . . . . . . . . . . . 48

Length Requried for a Fully

Developed Friction Factor . . . . . . 53 
IV. SUMMARY, CONCLUSIONS, AND RECCOMENDATIONS . . . . 61

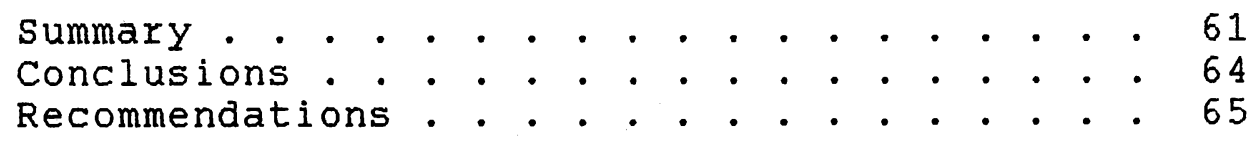

REFERENCES . • • . . . . . . . . . . . . . . . 67

APPENDICES . • • • . . . . . . . . . . . . . . . 70

APPENDIX A - DATA SOURCE . . . . . . . . . . 71

APPENDIX B - SAMPLE CALCULATION. • . . . . . . 73

APPENDIX C - UNCERTAINTY ANALYSIS. • . . . . . 77

APPENDIX D - COMPUTER PROGRAMS USED IN

THE STUDY • • • • • • • • • • • • • 81

APPENDIX E - THERMOPHYSICAL PROPERTIES OF

WATER AND ETHYLENE GLYCOL

MIXTURES • • • • . . . . . . . . 92 


\section{LIST OF TABLES}

Table

Page

I. Friction Factor Correlations for a Smooth Circular Duct. . . . . . . . . . . . 4

II. Fully Developed skin Friction Coefficients and the Fluid Concentrations Used to obtain Them. . . . . . . . . . . . . . . 43 


\section{LIST OF FIGURES}

Figure

Page

2.1 Schematic of the Experimental setup . . . . . . . 13

2.2 Schematic of the Test section . . . . . . . . 16

2.3 Schematic of the Pressure Tap Manifold. . . . . 18

2.4 Schematic of the calming and Inlet sections . . . 20

2.5 Schematic of the Mixing Well. . . . . . . . . 22

2.6 Calibration Data for the small Turbine Meter. . . . 32

2.7 Calibration Data for the Large Turbine Meter. . . 33

2.8 Calibration Data for the Test section . . . . . 35

3.1 Moody Diagram . . . . . . . . . . . . . . 45

3.2 Percent Deviation from the Laminar skin Friction Coefficient. . . . . . . . . . . 46

3.3 Percent Deviation from the Turbulent skin Friction Coefficient. . . . . . . . . . . . 47

3.4 Moody Diagram of the Transition Region. . . . . . 49

3.5 Percent Deviation from the Transition skin Friction Coefficients . . . . . . . . . . 52

3.6 Laminar Flow Apparent Friction Factors. . . . . . 54

3.7 Laminar Friction Factors in the. Entrance Region . . . . . . . . . . . . 55

3.8 Turbulent Flow Apparent Friction Factors. . . . . 58

3.9 Turbulent Entrance Length . . . . . . . . . . 59 
NOMENCL ATURE

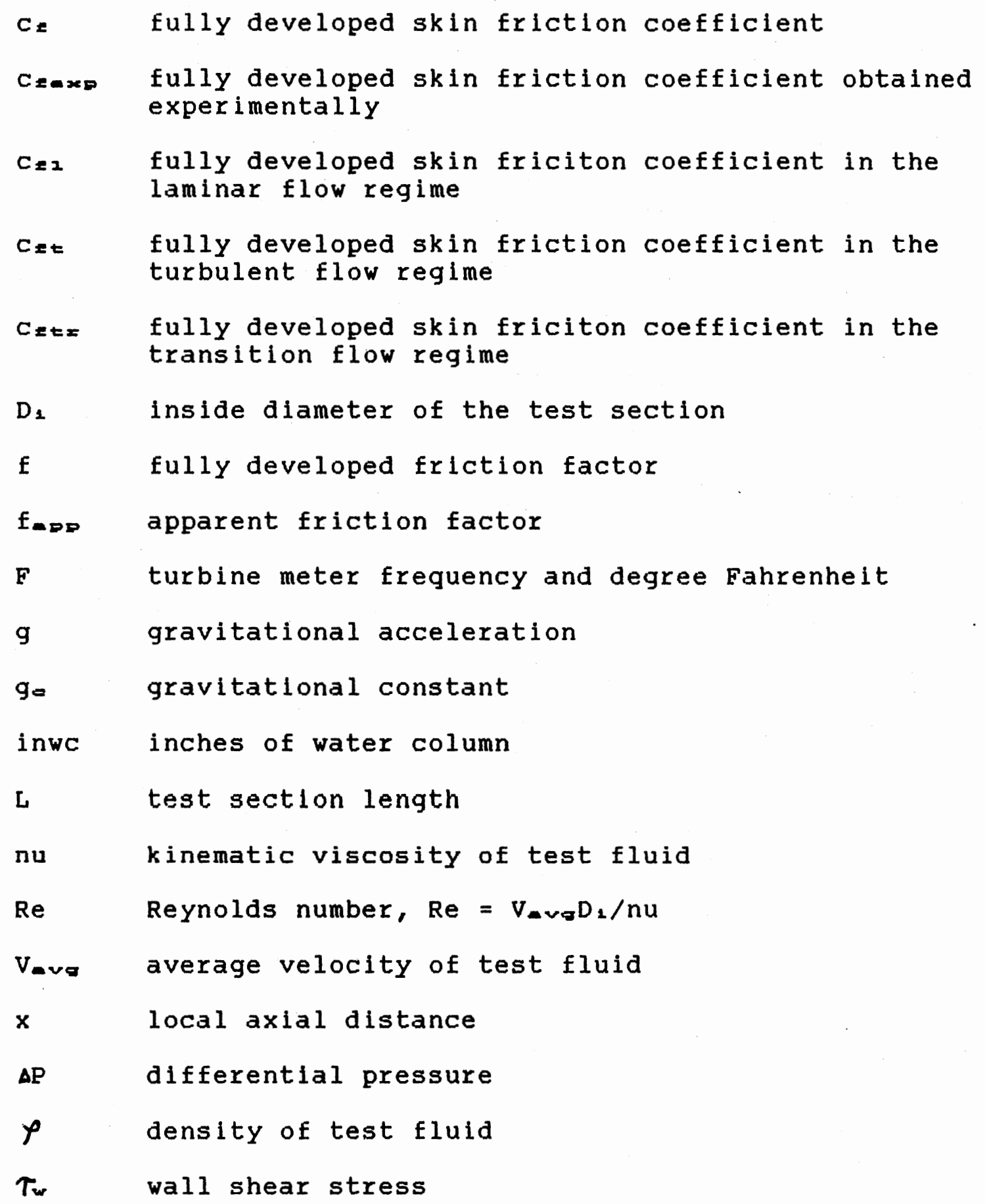




\section{CHAPTER I}

\section{NTRODUCT I ON}

An important design problem in industrial heat exchangers arises when the flow inside the tubes falls in the transition region between laminar and turbulent flow. The Reynolds number where transition begins to occur, the critical Reynolds number, for smooth round tubes can vary from 2000 to 10000 in extreme cases. An enormous amount of data and analytical modeling is available for fluid flow processes in tubes in the laminar and fully-turbulent flow regimes. However, very little has been done to investigate the problems encountered in the transition flow regime. In practical engineering design, the usual recommendation is to avoid design and operation in this flow regime; however, this is not always feasible under design constraints. It is the purpose of this study to provide information about this flow regime for use by both the engineering designer and the academician.

This study was performed concurrently with a study of heat transfer measurements in the transition region for a circular tube with a square-edged entrance, strickland (1990). Future studies of the transition region will involve pressure drop and heat transfer measurements with different inlet conflgurations, pressure drop measurements under a 
constant wall heat flux condition, intermittency measurements under constant wall heat flux and isothermal conditions, and flow visualization. This chapter discusses the reasons for research, the objectives, and the method of approach.

\section{Reasons for Research}

It should be noted that there are two common standards in the specification of friction coefficients used in the literature, the Fanning Friction Factor is denoted by "cs" and the Moody Friction Factor is denoted by "f". In this study, when the term "skin friction coefficient" is used it is referring to the Fanning standard. The Moody standard is used only when referring to apparent friction factor, faps. The discrepancy arises from the method in which the friction coefficients were derived. The two friction coefficients differ by a factor of four. For example, in the laminar flow regime $C_{x}=16 / \mathrm{Re}$ and $E=64 / \mathrm{Re}$. One must use caution when using friction coefficient correlations to realize which standard is being used.

The skin friction coefficient is defined in Equation (1.1) and the apparent friction factor is defined in Equation (1. 2).

$$
\begin{gathered}
C==\frac{\Delta P D}{2 L \varphi V_{\Delta v g^{2}}} \\
E_{a D D}=\frac{P \Delta-x D}{\frac{1}{2} \times \varphi V_{a v \sigma^{2}}}
\end{gathered}
$$


In Equation (1.2) the term " $\Delta \mathrm{P}_{0-x "}$ refers to the pressure drop from the inlet to a specific point down the tube.

In order to successfully predict pumping power requirements in industrial applications of viscous flows through smooth round tubes skin friction coefficient correlations are required. There are several skin friction coefficient correlations available. Table I states the presently available skin friction coefficient correlations for the laminar, transition, and turbulent flow regimes, Bhatti and shah (1987). The correlations in Table I are denoted by "f" but utilize the Fanning standard.

The skin friction coefficient correlation for fully developed laminar flow is obtained through elementary fluid dynamics theory and has long since been known, $c_{z}=16 /$ Re.

The correlation proposed by shah (1977) for the apparent friction factor, foso, for laminar flow is applicable only for a smooth circular duct with a short bell-mouthed entrance. The apparent friction factor, fapo, is defined as a friction coefficient which takes into account pressure drop in a tube caused by friction between the fluid and the tube wall and also pressure drop caused by the momentum flux in the development of the velocity profile. There are presently no available correlations for apparent friction factors in the transition and turbulent regions.

There are presently three available correlations for predicting fully developed skin friction coefficients in the transition region developed by Bhatti \& Shah (1987), 
FRICTION FACTOR CORRELATIONS FOR A SMOOTH CIRCULAR DUCT

\begin{tabular}{|c|c|c|}
\hline INVESTIGATOR & CORRELATION & $\begin{array}{l}\text { RECOMMENDED } \\
\text { RE RANGE }\end{array}$ \\
\hline Shah & $\begin{array}{c}f_{\text {app }}=\frac{1}{\operatorname{Re}}\left[\frac{3.44}{\zeta^{1 / 2}}+\frac{0.31 / \zeta+16-3.44 / \zeta^{1 / 2}}{1+0.00021 / \zeta^{2}}\right] \\
\text { where } \zeta=(X / D) / \operatorname{Re} \\
f_{\text {app }}=\text { apparent friction factor }\end{array}$ & Laminar \\
\hline Churchill & $\frac{2}{f}=\left\{\frac{1}{\left[(8 / R e)^{10}+(\operatorname{Re} / 36.500)^{20}\right]^{1 / 2}}+\left[2.21 \ln \left(\frac{\operatorname{Re}}{7}\right)\right]^{10}\right\}^{1 / 5}$ & Laminar. Transition and Turbulent \\
\hline Hrycak \& Andruskriw & $f=-3.10 \times 10^{-3}+7.125 \times 10^{-6} R e-9.70 \times 10^{-10} R e^{2}$ & 2.100 to 4.500 \\
\hline \multirow[t]{2}{*}{ Bhatri \& Shah } & $f=A+\frac{B}{R e^{1 / m}}$ & 2,300 to $10^{7}$ \\
\hline & $\begin{array}{l}\text { where } A=0.0054, B=2.3 \times 10^{-8}, m=-\frac{2}{3} \\
\text { for } 2.300 \leq \operatorname{Re} \leq 4.000 \text { and } A=1.28 \times 10^{-3} \\
B=0.1143, m=3.2154 \text { for } 4.000 \leq \operatorname{Re} \leq 10^{7} \text {. }\end{array}$ & - \\
\hline Blasius & $f=0.0791 R e^{-0.25}$ & $4 \times 10^{3}$ to $10^{5}$ \\
\hline McAdams & $f=0.046 R e^{-0.2}$ & $3 \times 10^{4}$ to $10^{6}$ \\
\hline Bhari \& Shah & $f=0.0366 \operatorname{Re}^{-0.1818}$ & $4 \times 10^{4}$ to $10^{7}$ \\
\hline Nikuradse & $f=0.0008+0.0553 R^{-0.237}$ & $10^{5}$ to $10^{7}$ \\
\hline
\end{tabular}


TABLE I (Continued)

\begin{tabular}{|c|c|c|}
\hline INVESTIGATOR & CORRELATION & $\begin{array}{l}\text { RECOMMENDED } \\
\text { RE RANGE }\end{array}$ \\
\hline Drew et al. & $f=0.0014+0.125 R e^{-0.32}$ & $4 \times 10^{3}$ to $5 \times 10^{6}$ \\
\hline Bhati \& Shah & $f=0.00128+0.1143 R e^{-0.311}$ & $4 \times 10^{3}$ to $10^{7}$ \\
\hline $\begin{array}{l}\text { Prandll } \\
\text { Karman } \\
\text { Nikuradse }\end{array}$ & $\frac{1}{\sqrt{f}}=1.7372 \ln (\operatorname{Re} \sqrt{f})-0.3946$ & $4 \times 10^{3} 1010^{7}$ \\
\hline Colebrook & $\frac{1}{\sqrt{f}}=1.5635 \ln \left(\frac{\mathrm{Re}}{7}\right)$ & $4 \times 10^{3}$ to $10^{7}$ \\
\hline Filonenko & $\frac{1}{\sqrt{f}}=1.58 \ln \operatorname{Re}-3.28$ & $10^{4}$ to $10^{7}$ \\
\hline Techo et al. & $\frac{1}{\sqrt{f}}=1.7372 \ln \frac{R e}{1.964 \ln R e-3.8215}$ & $10^{4}$ to $10^{7}$ \\
\hline
\end{tabular}


Churchill (1977), and Hrycak \& Andruskiw (1974). The correlations are listed in Table I. Churchill's correlation is valid for all three fully developed flow regimes but the Reynolds number ranges for Bhatti \& Shah's and Hrycak \& Andruskiw's correlations are 2300 to 4000 and 2100 to 4500 , respectively. However, these correlations are based on data obtained from making pressure drop measurements on a smooth round tube with a rounded entrance. This study will provide information and correlations associated with this flow regime in a circular tube with a square-edged entrance.

For Reynolds numbers between 4000 and 100000 the well established Blasius turbulent skin friction coefficient correlation is available. For a smooth round tube with square-edged entrance the lower limit for this correlation is not well defined.

Table I also presents the other available skin friction coefficients for fully developed turbulent flow. Some of their Reynolds number ranges touch on the range used in this study but they are generally used for turbulent flows with higher Reynolds numbers.

Many heat transfer correlations for round tubes involve the use of a skin friction coefficient. The data provided by this study will aid in the development of heat transfer correlations for smooth round tubes with a square-edged entrance.

With the advent of hot-film anemometry the concept of intermittency has been introduced into the field of fluid 
dynamics research. Intermittency is defined as a degree of turbulence with the intermittency factor being zero for a fully laminar flow and one for a fully turbulent flow. The work of Ogawa and Kawamura (1987) presents skin friction coefficient and heat transfer correlations for transition flows with several inlet configurations involving the intermittency factor. The data from this study will aid in developing similar correlations.

\section{Objectives}

The objectives for this study are as follows:

1. to construct a versatile experimental setup to make pressure drop measurements with different inlet configurations, under a constant wall heat flux condition, and to provide the ability to make intermittency measurements in the test section.

2. to define the range of Reynolds numbers where the transition region occurs for a smooth round tube with a square-edged entrance thereby determining at what Reynolds numbers the fully developed laminar skin friction coefficient correlation is no longer valid and the Blasius fully developed turbulent skin friction coefficient correlation becomes valid.

3. to provide a correlation to predict fully developed skin friction coefficients in the transition region for this particular entrance and compare with those 
developed for rounded entrances.

4. to compare the experimentally obtained skin friction coefficients with those 1 isted in Table I for the fully developed laminar and turbulent flow regimes.

5. To determine what influences the square-edged entrance configuration has on the established laminar apparent friction factor correlation.

6. to develop guidelines for the development of the laminar and turbulent skin friction coefficients in the entrance region of a smooth round tube with a square-edged entrance.

7. to provide valuable data to later develop heat transfer correlations using skin friction coefficients.

8. to provide data to later develop skin friction coefficient correlations involving the concept of intermittency.

Method of Approach

The current work focuses on the study of fully developed skin friction coefficients in the transition flow regime and establishing the Reynolds number limits for this regime in a smooth round tube with a square-edged entrance. The well established laminar and fully turbulent flow regimes will also be studied to determine what effects this particular entrance configuration has on these flow regimes and relate 
those observations to those made for the transition flow regime.

To make these observations pressure drop measurements will be made on a horizontal circular tube with a length to diameter ratio of 386. Although air is much easier fluid with which to perform this task, liquids will be used. A study of heat transfer in the same flow regime with the same entrance conflguration will be performed concurrently with this study. By using liquids a greater range of Prandtl numbers can be achleved which will provide better data for developing heat transfer correlations. Therefore it is important to use liquids for the pressure drop measurements so the data can be used with greater confidence to make comparisons with the heat transfer data and so that heat transfer correlations involving skin friction coefficients can be developed more readily. The fluids to be used will be distilled water, ethylene glycol, and solutions of distilled water and ethylene glycol. The three types of fluids are necessary to provide a greater range of Reynolds numbers due to their range of viscosities.

The horizontal circular tube will be equipped with twenty-one pressure taps. The spacing and orientation of the pressure taps is displayed in Figure 2.2. The number of pressure taps was well thought out so as to provide as much information in the entrance region as possible without putting an excessive number of holes in the tube to distract from the characteristics of a smooth tube. Each of the 
pressure tap holes was to be deburred with a special tool, described in Chapter II, to further ensure the characteristics of a smooth tube.

Preliminary calculations predicted the majority of the pressure drops for the experimental setup in the Reynolds number ranges required for the three types of fluid used to be between zero and fifty inches of water. The pressure drop between the closest spaced pressure taps was estimated to be as low as 0.1 inwc. There are presently no accurate differential pressure transducers that digitally measure differential pressures of liquids in this range. It was decided to use three analog differential pressure gauges, with increasing ranges, and a mercury manometer to make the necessary pressure drop measurements.

Upon studying the work of Shapiro and Smith (1957) a pressure gauge manifold was to be constructed. This manifold would allow pressure drop measurements to be made from the reference pressure tap to any of the other twenty pressure taps.

In order to reduce the pressure drop measurements to skin friction coefficients the thermophysical properties of the fluid had to be accurately determined. The work of Bohn, et al. (1984) presents equations for the thermal conductivity, density, viscosity, and Prandtl numbers of ethylene glycol-water mixtures for any concentration on a mass basis. These equations, listed in Appendix E, were incorporated into a computer program to calculate all of the 
pertinent thermophysical properties of a given concentration of fluid for a given bulk temperature at given volume flow rate. This computer program, "ETH", and a comparison of its computed values with other sources is listed in Appendices D and $E$, respectively. 


\section{CHAPTER II}

\section{EXPERIMENTAL APPARATUS}

Pressure drop measurements in the transition flow regime were studied in a horizontal circular tube with a squareedged entrance. The pressure drop study was part of a larger study that encompassed pressure drop and forced and mixed convective heat transfer measurements under a constant wall heat flux condition in the same flow regime with different inlet configurations. The experimental setup is shown in Figure 2.1. A versatile setup was required so that the effects of different inlet configurations and the effects of a uniform wall heat flux condition on pressure drop could be later studied. Distilled water, ethylene glycol, and ethylene glycol-water solutions were used as test fluids. The experimental setup, calibration procedure, experimental procedure, and method of data reduction are described as follows.

Description of the Equipment

\section{Test section}

The test section was a seamless 316 stainless steel circular tube with an average inside diameter of $0.621 \pm$ 0.002 inches $(15.8 \mathrm{~mm} \pm 0.013 \mathrm{~mm})$ and outside diameter of 


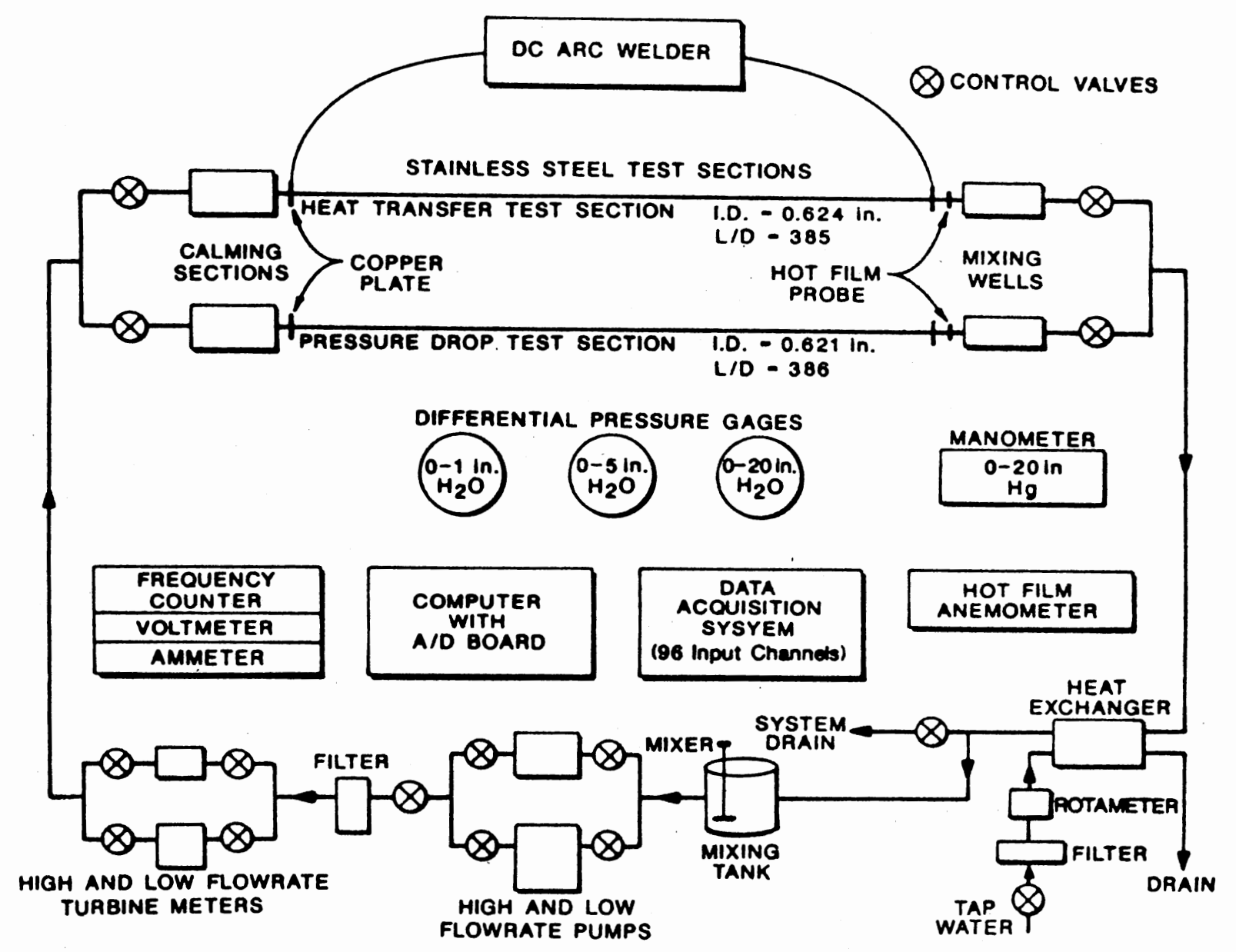

Figure 2.1 Schematic of the Experimental Setup 
$0.752 \pm 0.001$ 1nches $(19.1 \mathrm{~mm} \pm 0.007 \mathrm{~mm})$. The total length of the test section was 230.75 inches $(5.861 \mathrm{~m})$ providing a length to diameter ratio (L/D) of 386 . The test section was purchased from the precision Tubing and Fitting Co. of Tulsa, Oklahoma. The test section was wrapped with fiberglass pipe insulation and vapor seal. The total thickness of these materials was approximately one inch. The test section was leveled with the use of a surveying transit and wooden spacers. The leveling of the test section was checked once a week throughout the study.

Although not used in this study, at the end of the test section a rectangular aluminum housing for the hot film probe was heat expanded, positioned, and cooled to a water-tight fit over the test section. The housing was $2.5^{\prime \prime} \times 2.25^{\prime \prime} \times$ 1.5" and had an additional hole machined to allow for the insertion of the probe. A slot through the test section also had to be machined to allow for the insertion of the probe. The probe housing and the slot were machined by personnel at the Mechanical Engineering North Labs at oklahoma state University.

Equipment for Generating a constant Wall Heat Flux Condition

Although not used in this study, copper plates were silver soldered near the inlet and exit of the test section, as shown in Figure 2.2, for the purpose of attaching welding cables to subject the test section to a constant wall heat flux. The inlet plate was $1 / 4 " \times 10^{\prime \prime} \times 10^{\prime \prime}$ and the exit 
plate was $1 / 4^{\prime \prime} \times 5^{\prime \prime} \times 5^{\prime \prime}$. Supporting copper material and bus bars were bolted to the plates were sized to conform to the space limitations of the apparatus.

The heat flux source is a Lincoln Idealarc DC-600 three phase rectified type electric welder and will be used with variable voltage to produce a DC electric current through the test section. The welder has maximum power output of 26.4 KW.

To ensure minimal room heating and vibration effects from the welder it was located near an external wall where cooling air could be brought in from outside the room and exhausted outside the room through custom made plenums. Much of the exhaust noise will be alleviated in this manner. In order to prevent the welder from transmitting vibrations through the room, a 37" x 41" x 57" plywood box was placed over the welder. The sides of the box were lined with two inches of duct insulation. Ten refrigerator type damping pads were placed on the bottom of the welder to prevent the transmission of vibration through the floor.

\section{Pressure Taps}

Twenty-one holes of $5 / 64 "(1.98 \mathrm{~mm})$ diameter were drilled in the test section to accommodate twenty-one pressure taps. When drilling for the pressure taps, one has to ensure that the ratio of the tube wall thickness to tap hole diameter, $t / D$, is greater than 1.0 for minimum error, Benedict (1984). The diameter of the holes that were 



1 PRESSURE TAP 2 THERMOCOUPLES

THERMOCOUPLES CORRESPOND

TO STATIONS: $1.4,6.9,13,17,19.21$.

23.27.31 OF HEAT TRANSFEA

TEST SECTION

Figure 2.2 Schematic of the Test Section 
drilled was $5 / 64 "$ because that is the smallest size in which the deburring tool is available. The tap diameter used gave a t/D ratio of 0.82 which is close to 1.0 and is not belived to have induced any significant error. The hole spacing and pressure tap orientation is shown in Figure 2.2. After the holes were drilled they were followed with a deburring tool manufactured by Reynolds Tool Products (Anaheim, CA), Model \# T-A BA 5/64. The holes had to be deburred in order to ensure the characteristics of a smooth tube, thus eliminating excess pressure drop and the onset of false transition flow. The pressure taps were standard saddle type self-tapping valves (1/2" - $11 / 2 "$ capacity) with the tapping core removed. 1/4 inch I.D. vinyl tubing was used to connect the pressure taps to the pressure tap manifold.

\section{Pressure Tap Manifold}

A pressure tap manifold was constructed in order to make sequential pressure drop measurements down the test section (i.e. isolate different lengths of the test section in order to make pressure drop measurements from the reference pressure tap to the desired pressure tap). This apparatus is shown in Figure 2.3. The manifold consisted of five sections containing four valves each. The valves were PVC ball valves with 1/4" NPT threads on one end and a 1/4" - 3/8" hose barb on the other. They were purchased from the Industrial Plastics Corp. Each section was essentially a 1.5" $x 1$ " $x$ " aluminum block with a 0.125 inch hole drilled through the 


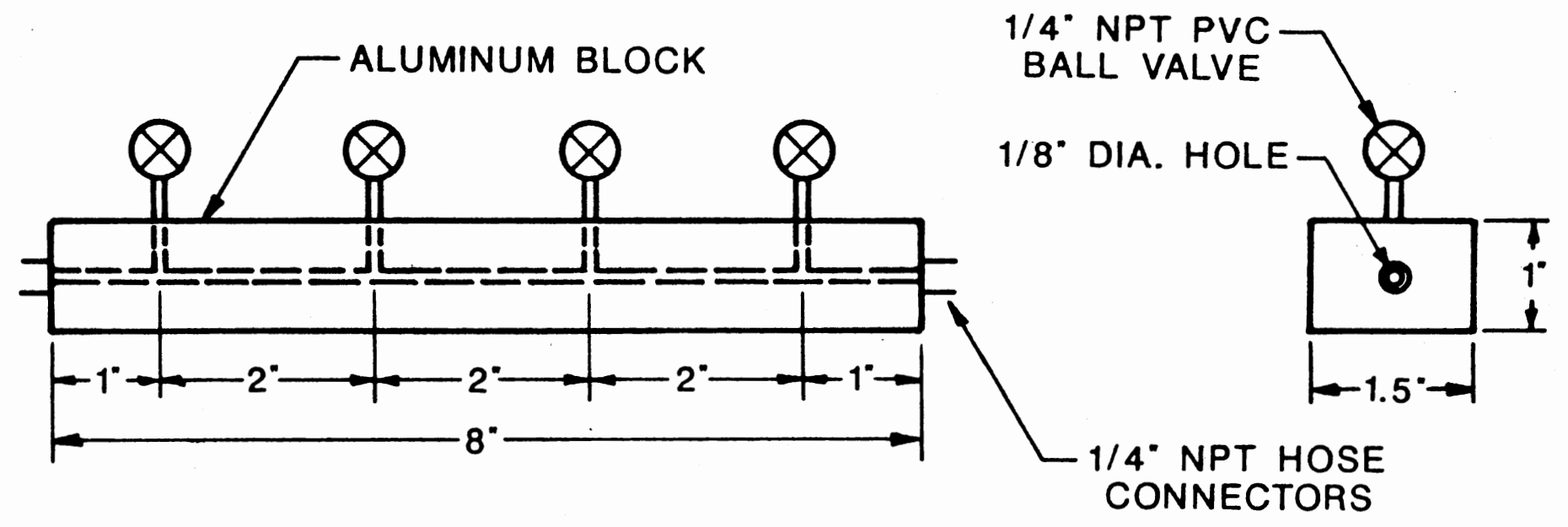

TO INDIVIDUAL

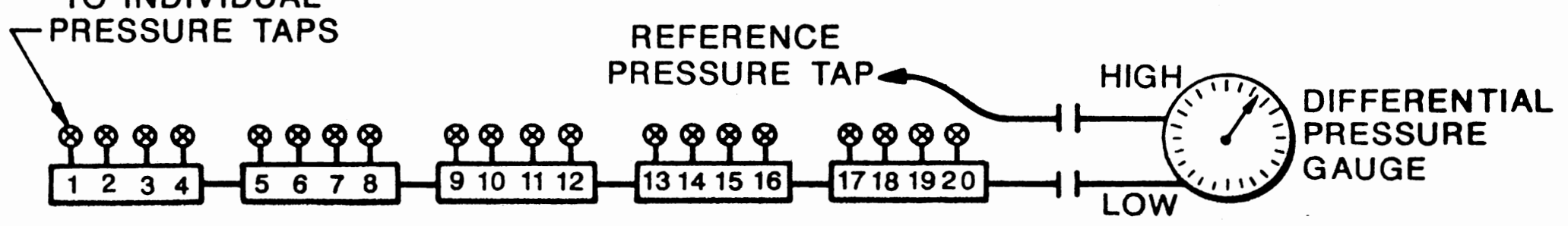

Figure 2.3 Schematic of the Pressure Tap Manifold 
center. Four holes were drilled through the top and tapped to accommodate the ball valves.

\section{Calming and Inlet sections}

The calming and inlet sections, made from acrylic plastic, were used to produce a uniform velocity distribution in the test fluid before entering the test section. The combination of the inlet section and the test section produced a square-edged entrance configuration for the test section. The calming and inlet sections and their dimensions are shown in Figure 2.4. The flow entering the calming and inlet sections encountered: 1) Three screens which were machined from $1 / 2$ inch acrylic plastic and contained $7 / 16$ " diameter holes on a 0.6 inch equilateral triangular pitch; 2) A 23 gauge galvanized steel mesh followed by tightly packed soda straws and another 23 gauge mesh; and 3) An aluminum insect screen mesh supported by 23 gauge galvanized steel mesh. These components were encased by a 7 inch O.D. plexiglass tube of $3 / 16$ inch wall thickness. These components were held in place by spacers constructed from 6 and $1 / 2$ inch plexiglass tube of $3 / 16$ inch wall thickness. After the test fluid encountered these flow straighteners it flowed undisturbed through the inlet section, 9.25 inches of a 6 and $1 / 2$ inch plexiglass tube. This was done to ensure a uniform velocity distribution upon entering the test section. The calming and inlet sections were also equipped with air bleed valves which were used to evacuate air during 


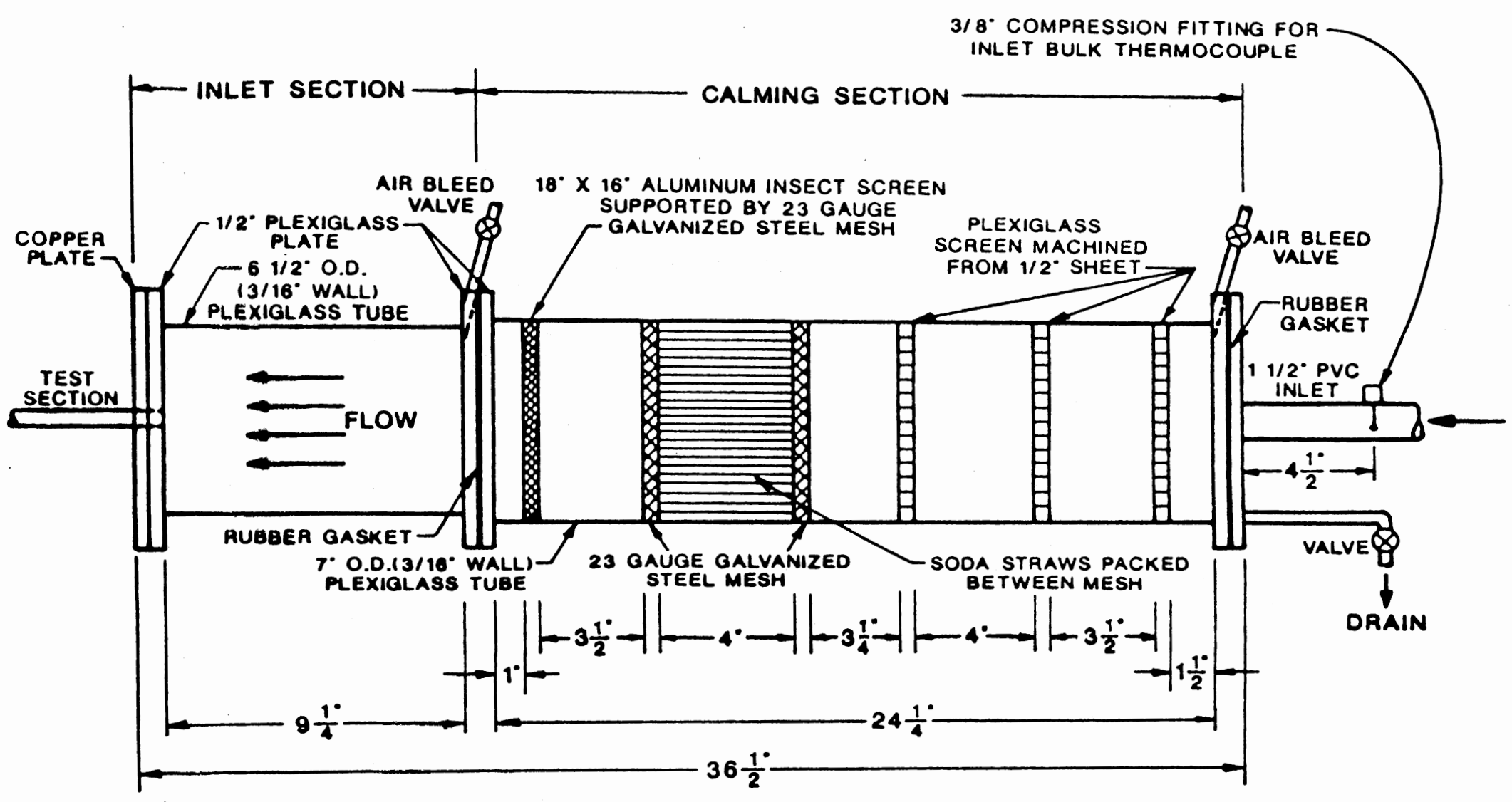

Figure 2.4 Schematic of the Calming and Inlet Sections 
start up.

The inlet section had the versatility of easily being modified to incorporate a re-entrant, bell-shaped, or any other inlet configuration deemed feasible.

\section{Mixing Well}

To ensure a uniform fluid bulk temperature at the exit of the test section a mixing well was utilized. The mixing well was constructed from high temperature 1.25 inch schedule 40 CPVC pipe and is shown in Figure 2.5. Alternating acrylic baffles were placed in the well oriented from the top and from the bottom blocking $60 \%$ of the internal flow area. The baffles were held in place with a silicon sealant. These baffles caused the flow to be vigorously mixed thus ensuring a uniform bulk temperature at the exit of the mixing well. Near the end of the mixing well a T-type thermocouple (TT-T-30), permanently fixed inside a $1 / 4$ inch aluminum tube approximately 2.5 inches long, was inserted into the flow area through a brass compression fitting. The mixing well is connected to the test section by an acrylic reducing adaptor cemented inside a 1.25 inch CPVC coupling.

\section{Thermocouples}

Although they were not used in this study, twenty-two thermocouples (Omega TT-T-30) were cemented with Omegabond 101 to the outside of the test section in the orientation shown on Figure 2.2. Omega EXPP-T-20 extension wire was used 


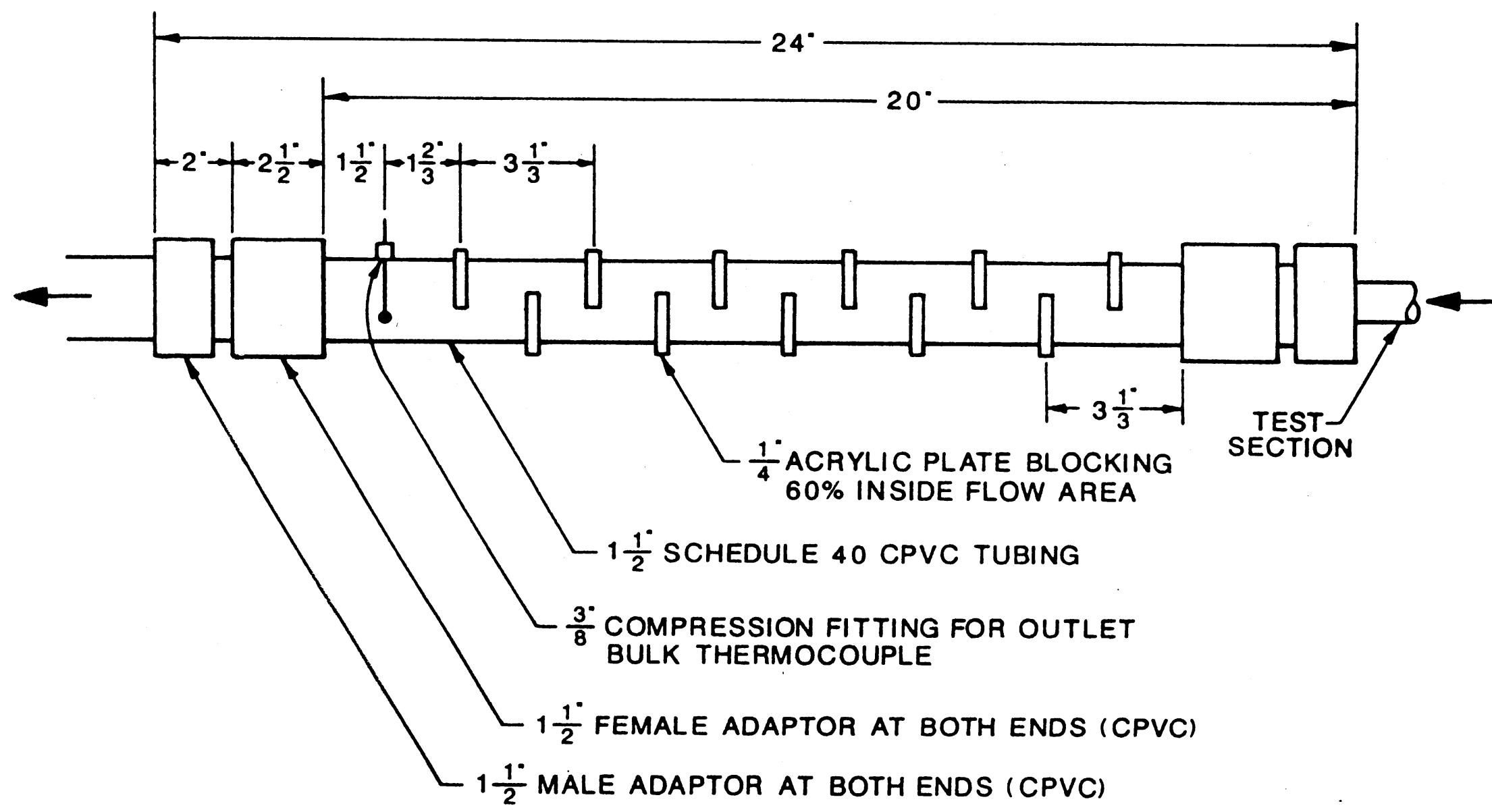

Figure 2.5 Schematic of the Mixing Well 
for all the thermocouples. This was done to allow a more flexible experimental setup so that pressure drop measurements under a constant wall heat flux condition could be performed for a later study.

For this study one thermocouple was placed 4.5 Inches before the entrance to the calming section in the 1.5 inch PVC pipe as shown in Figure 2.4. One thermocouple was also placed at the exit of the mixing well as shown in Figure 2.5 . These thermocouples were mounted in the same manner as those used for the heat exchanger and were used to monitor the inlet and exit bulk temperatures of the test fluid. These thermocouples were monitored with ECD 5100 Forty Channel Data Logger manufactured by Electronic Controls Design.

\section{pumps}

For low flow rates a pump manufactured by Little Giant Pump Co., model 4-MD, was used. It produced a maximum flow rate of $4.5 \mathrm{gpm}$ at $3100 \mathrm{rpm}$ using a $1 / 12 \mathrm{hp}$ motor. For high flow rates a pump manufactured by oberdorfer Pumps, model SKH35FN193T, was used. It produced a maximum flow rate of 11 gpm at $3450 \mathrm{rpm}$ using a General Electric $1 / 3 \mathrm{hp}$ motor.

To minimize the vibrations produced by the pumps during operation they were mounted inside a plywood box using rubber damping material approximately $3 / 8$ inches thick. The box had dimensions of 57 inches-wide, 30-inches high, and 16-inches deep. The interior walls of the box were lined with one inch of duct insulation and the entire box was isolated from the 
floor with twelve refrigerator type rubber dampers to suppress additional vibrations. In addition, rubber hoses were connected to the pump box at both the upstream and downstream ends to prevent vibration transmission to the fluid return tubing.

\section{Turbine Meters}

For low flow rates a Cox Flowmeters, model AN $8-6,1 / 2$ inch turbine meter was used over a frequency range of 140 to $1140 \mathrm{~Hz}$ accommodating flow rates from 0.5 to $6.0 \mathrm{gpm}$. For high flow rates a Halliburton 1 inch turbine meter was used over a frequency range of 50 to $150 \mathrm{~Hz}$ accommodating flow rates to $10.5 \mathrm{gpm}$. Both turbine meters had a linearity of $+0.5 \%$ of reading and a repeatibility of less than $+0.10 \%$ of reading.

The turbine meters were incorporated into an assembly using 1.5 inch PVC ball valves at both ends of each to ensure no fluid entrainment from the one which is inactive at any given time. The calibration procedures for the turbine meters are detailed in the calibration section of this chapter.

\section{Erequency counter}

A Hewlett-Packard model 5314A universal counter was used to indicate the frequency of the turbine meters during operation. The input frequency range for the $5314 \mathrm{~A}$ is $10 \mathrm{~Hz}$ to $100 \mathrm{MHz}$, with a sensitivity of 25 millivolts rms to 100 
MHz, and 0.075 volts peak to peak at a minimum pulse of 5 nanoseconds. The resolution and accuracy are to the least significant digit, LSD.

During operation of the turbine meters at low frequency, Erequency instability problems were observed. To solve this problem, a variable gain amplifier was constructed by an Instruments Technician in the Mechanical \& Aerospace Engineering Instruments shop. It had a gain from one to five to produce a stable signal at low frequencies.

Heat Exchanger

A $21.2-\mathrm{ft}^{2}\left(1.97-\mathrm{m}^{2}\right), 1-2$ shell and tube heat exchanger manufactured by the ITT standard Company (Model BCF \#04036) was used to keep the test fluid at a constant temperature. The heat exchanger had a maximum duty of 67190 Btu/hr $(19.7 \mathrm{KW})$. It was purchased from the Thermal Engineering Co. of Tulsa, oklahoma. The cooling fluid was utility water and Its 1 ine was equipped with an Omega FL-9028 rotameter with a Elow rate range of 4 to $28 \mathrm{gpm}$, an accuracy of $\pm 5 \%$ full scale, and a repeatability of $\pm 1 \%$ full scale. The cooling water 1 ine was also equipped with a Teel Water systems model 2P227 double cartridge filter to remove impurities and avoid fouling in the heat exchanger. A 1.25 inch schedule 40 PVC pipe carried the cooling water to the exchanger and away from the exchanger to the waste water trough. Four TT-T-30 thermocouples, mounted inside $1 / 4$ inch aluminum tubes approximately two inches long with silicon sealant, were 
inserted through brass compression fittings. These assemblies were mounted in the PVC pipes near the heat exchanger to monitor the four stream temperatures with the ECD 5100 Data Logger.

\section{Differential Pressure Gauges and Manometer}

To measure the small differential pressures created by the transition flow of a liquid, three differential pressure gauges were used. The gauges were manufactured by the Dwyer Instrument Corporation and were models Capsuhelic 4001-B, 4005-B, and 4020-B. Their ranges were 0-1 inwc, 0-5 inwc, and 0-20 inwc, respectively. The postscript "B" refers to the fact that optional brass cases had to be used because of the water based test fluid.

For differential pressures greater than 20 inwc the differential pressures could be accurately measured with a mercury manometer. For this case a 20 " U-tube mercury manometer was used. It was manufactured by the Meriam Instrument Corporation, model \# 10AA25WM.

Quick disconnect fittings purchased from the Cole-Palmer Corporation were used to connect each of the pressure gauges and the manometer to the pressure tap manifold.

\section{Reservolr}

A 16 gallon cylindrical polyethylene tank, cover, and mixer were purchased from the Industrial Plastics Corp. The tank was sixteen inches in diameter and twenty-one inches in 
height. The mixer, used to ensure a uniform temperature distribution in the tank, was equipped with a $1 / 40 \mathrm{hp} 1550$ rpm motor and mixing blade.

\section{Test Fluids}

Distilled water, $60 \%$ ethylene glycol (by mass), and $100 \%$ ethylene glycol solutions were used as test fluids. The ethylene glycol was purchased from the Delta Chemical Company. The distilled water was obtained from the oklahoma State University Chemical Engineering Department.

\section{Eluid Return Piping}

Since the test fluid may be heated, there is a high temperature 1.5 inch schedule 40 CPVC pipe running from the mixing well to the heat exchanger. Exiting the heat exchanger, standard 1 inch schedule 40 PVC pipe and a 1 inch PVC ball valve allows for system drain or return to the reservoir. Exiting the reservolr, the test fluid goes through $1 / 2$ inch schedule 40 PVC to the pump box. After the pump assembly a $1 / 2$ inch stainless steel ball valve is used for flow control before the fluid enters a Teel water systems model 2P227 double cartridge filter system using two model 1P753A cartridges. Essential to protect the fragile hot film probe, the filter removes impurities as small as 5 microns. The fluid is then carried through 1.5 inch schedule 40 PVC to the turbine meter assembly and from the turbine meter assembly to the calming section. 1.5 inch schedule 40 PVC 
ball valves were used to direct the flow to either of the two test sections or to the additional flow visualization test section.

\section{Experimental Calibrations}

ECD 5100 Data Logger

The model 5100 data logger required a calibration procedure outlined in the operation manual. To perform the calibration a precision DC voltage source was used. This voltage source manufactured by the Electronic Development Corporation, model MV116, had an accuracy of \pm 1 microvolt. With the data logger held on channel number one, a 2.00000 volt voltage was applied to the channel. The variable resistors within the unit were adjusted until the display indicated exactly 2.0000 volts.

\section{Thermocouples}

The inlet and exit bulk temperature thermocouples were calibrated using an ice-bath technique. The thermocouples were placed in an insulated bath of ice water and were connected to the ECD 5100 Data Logger using the same extension wire used throughout the study. After allowing the thermocouples to come to a steady state the temperature reading from the data logger was recorded. The thermocouples were accurate within a maximum of $\pm 0.5 \mathrm{~F}$ in all cases over the range of temperatures encountered. 


\section{Differential Pressure Gauges}

The 0-1 inwc differential pressure gauge was checked against a 0-1 inwc slant tube manometer (also manufactured by Dwyer). The two devices were placed in parallel and were subjected to an equal pressure provided by a compressed air jet. After making minor adjustments to the differential pressure gauge with the fine adjustment screw on the face of the gauge, the gauge and the manometer were in full agreement throughout the entire 0-1 inwc range. This calibration was checked three times during throughout the study. The fine adjustment screw was never adjusted except during calibration checks.

The 0-20 inwc gauge had a large enough range to allow it to be checked against the mercury manometer. To accomplish this the system had to be in operation in order to generate a pressure differential. Using the pressure conversion chart provided by Dwyer (converting inwc to in. $\mathrm{Hg}$ ), several differential pressures in the 10 to 20 inwc range were noted of the gauge and compared to the manometer readings. The gauge was adjusted accordingly using the fine adjustment screw on the face of the gauge until the gauge and the manometer were in full agreement. This procedure was repeated once a week throughout the study.

Once the 0-1. inwc gauge and the 0-20 inwc gauge were adjusted properly they could be used to adjust the $0-5$ inwc gauge. This was done by starting the system and running 
through a series of pressure drops from 0 to 5 inwc and using

- all three gauges. The 0-5 inwc gauge was adjusted so that a one inch reading on the $0-1$ inwc gauge corresponded to a one inch reading of the 0-5 inwc gauge. Similarly, the 0-5 inwc gauge was also adjusted so that five inch reading on the $0-20$ inwc gauge corresponded to five a inch reading on the $0-5$ inwc gauge. This procedure was repeated once a week throughout the study.

At no time were the differential pressure gauges out of adjustment by more than their accuracy reported by the manufacturer, $\pm 3 \%$.

\section{Turbine Meters}

The flow rate through the two turbine meters was calibrated against the frequency of the impeller rotation. The calibration required a stopwatch, frequency counter, and at least two persons. A tweny-five inch ruler graduated to 1/16 inches was taped to the inside of the reservoir. The pump was switched on and allowed to run for a few seconds until normal operation occurred and to allow the test fluid to reach a uniform flow. Noting the initial height and frequency, the reservoir level was allowed to drop in height at the instant the stopwatch was activated. The fluld passed through the entire system and exited to a catch container. At certain time increments during the fluid collection, the frequency indicated by the counter was recorded. When roughly three to five gallons of test fluid had drained from 
the reservolr, or a reasonable period of time had elapsed for the considered flow rate, the stopwatch and fluid flow were simultaneously stopped. The final height of the fluid in the reservoir was recorded and average frequency over the time interval was calculated. Using the time interval, reservoir diameter, and change in reservoir height, the volume flow rate was calculated. This volume flow rate was then correlated with the calculated average frequency. The procedure was repeated at representative values over the available frequency range of both turbine meters (approximately fifteen points). Each of these representative values were repeated three times to obtain averages. This averaged data was then correlated using a linear least squares curve fit. The minimum correlation coefficient attained was 99.90\%, the maximum was 99.99\%. Figures 2.6 and 2.7 illustrate the data collected for both meters and curve fits (including correlation coefficients) for all fluid concentrations used.

A computer program called "GPMCALC" was written to enable quick determination of flow rate given frequency or vice versa. This program is applicable for both turbine meters and all the fluid concentrations used. The complete program is listed in Appendix D.

\section{Calibration Runs}

To compare the accuracy of the experimental setup to the established skin friction coefficient correlations for 


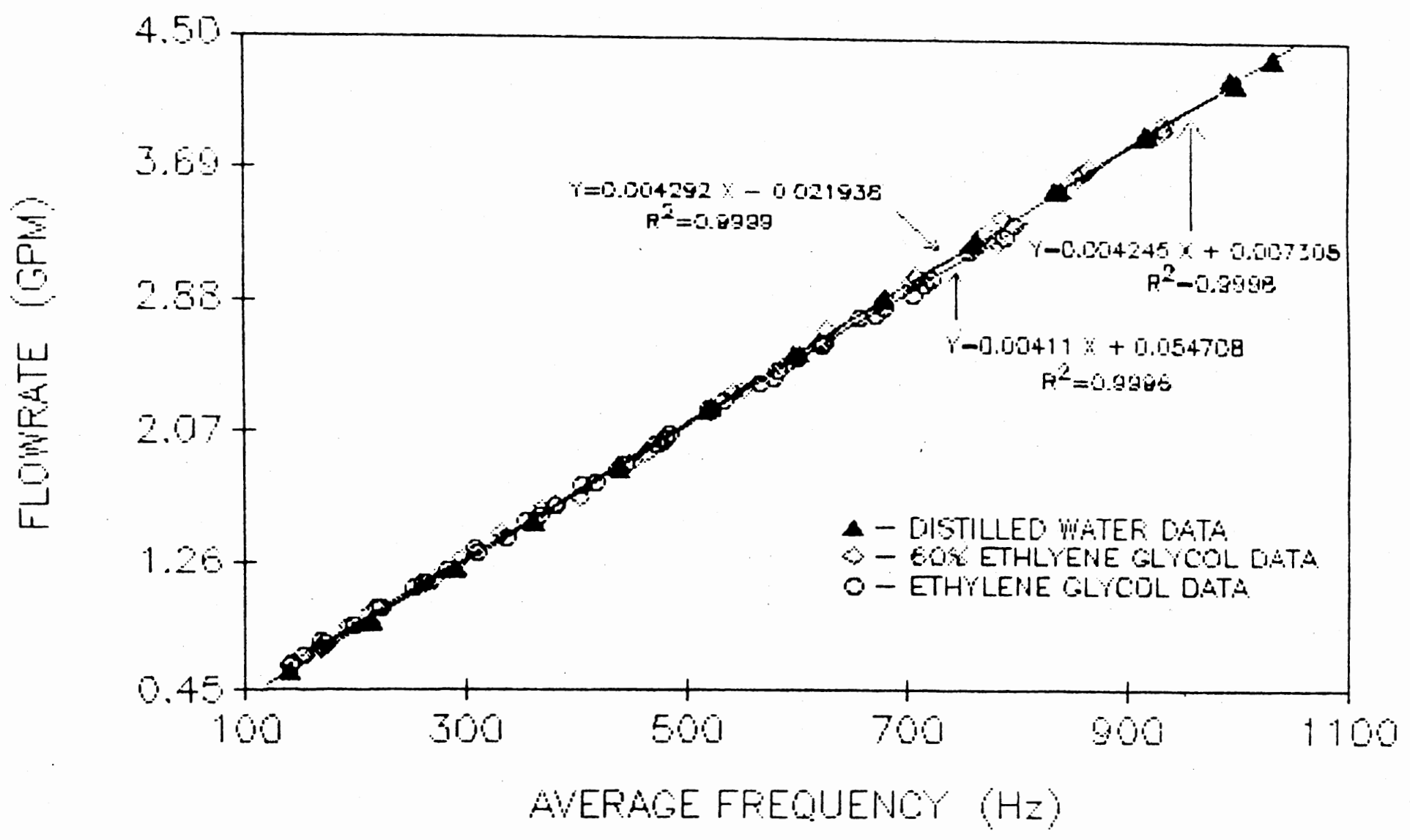

Figure 2.6 Calibration Data for the Small Turbine Meter 


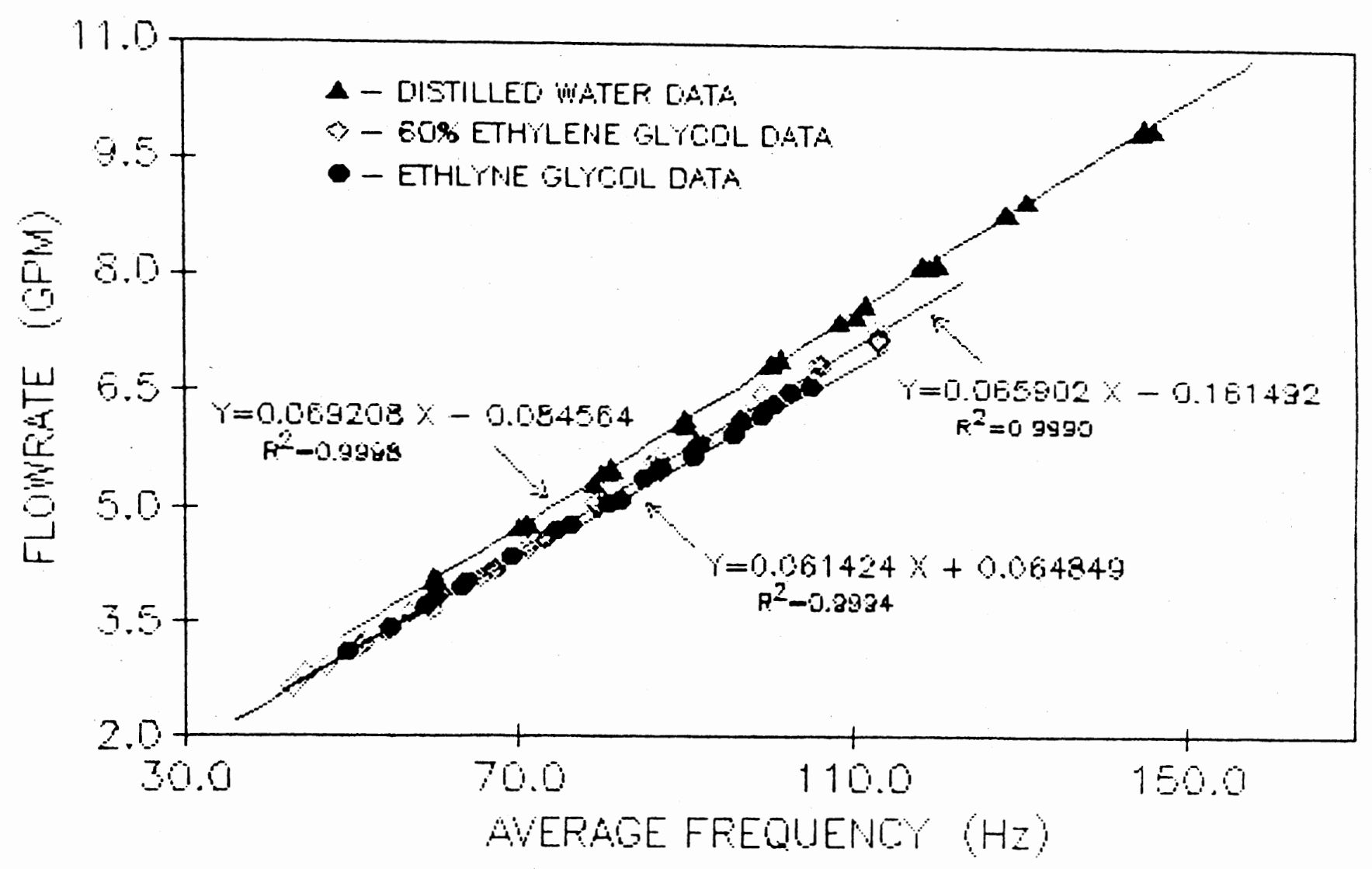

Figure 2.7 Calibration Data for the Large Turbine Meter 
turbulent flow, distilled water was subjected to steady state fully turbulent flow with Reynolds numbers greater than 10000. Five fully developed skin friction coefficients were obtained for Reynolds numbers ranging from 11030 to 14970 . The method used to obtain the fully developed skin friction coefficients was the same as that described in the section of this chapter on data reduction. When compared to the Blasius skin friction coefficient correlation for turbulent flow in round tubes, the experimental values obtained ranged from $-2.1 \%$ to $-4.6 \%$. The values were assumed to be well within the accuracy of the Blasius correlation. From this point the system was considered to be behaving as expected and the data was considered valid. This calibration data is shown in Figure 2.8.

$$
\text { start-Up and operating procedure }
$$

The following procedures were followed for each run:

1. All entrance and exit valves for the pressure drop test section were opened. All entrance and exit valves for the for the heat transfer test section were closed.

2. The entrance and exit valves for the desired turbine meter (high-flow or low-flow) were opened. The frequency counter and amplifier were turned on.

3. All valves on the pressure tap manifold were closed to avoid over pressurizing the differential pressure gauges. 


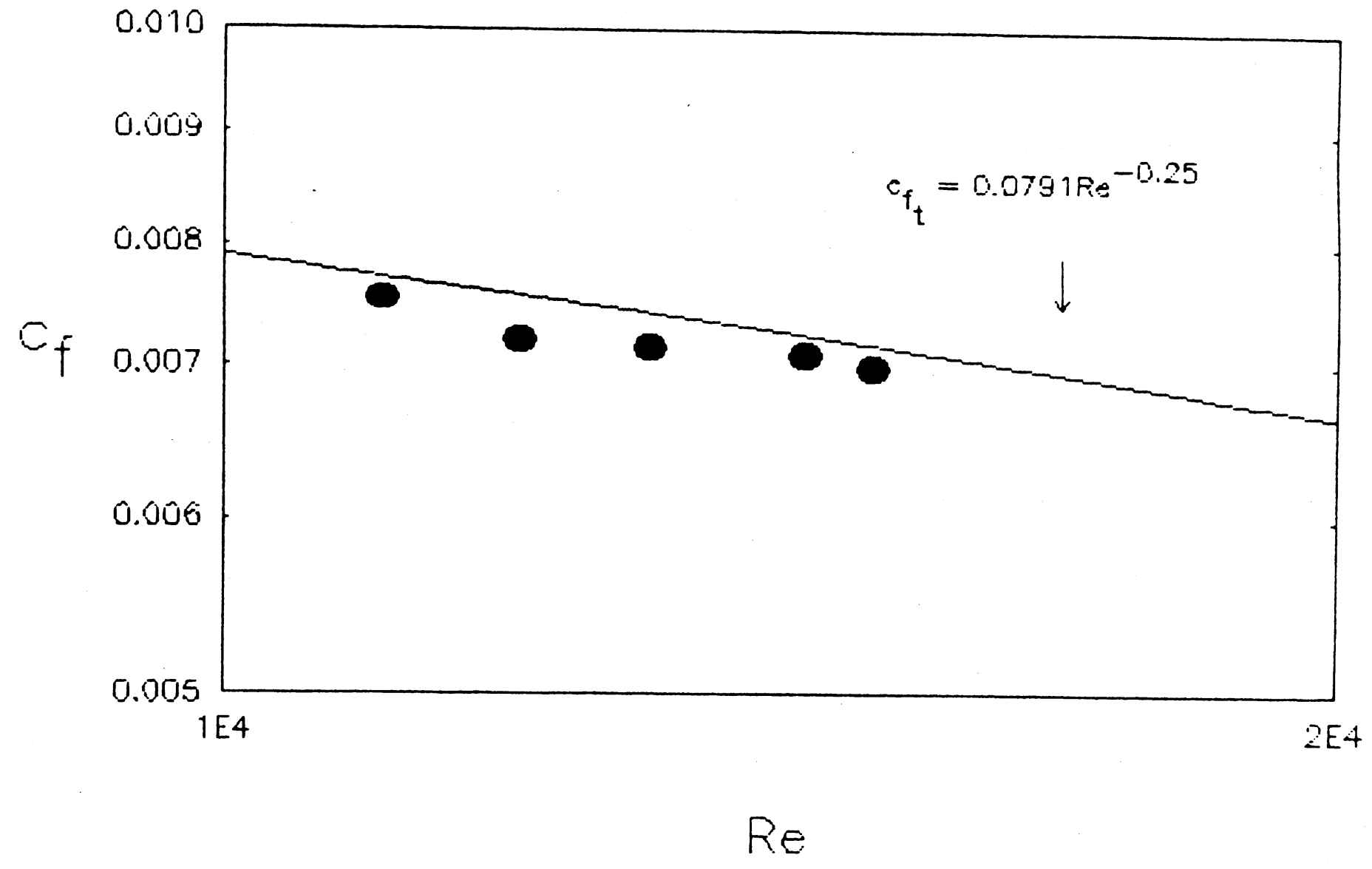

Figure 2.8 Calibration Data for the Test Section 
4. The entrance and exit valves for the desired pump (high-flow or low-flow) were opened and the pump turned on.

5. After checking for leaks on the entire test section, excess air was bled off of the calming and inlet sections.

6. The cooling water valve was opened ( $8 \mathrm{gpm})$ for the purpose of removing the heat added to the test fluid by the pump thereby allowing steady state conditions.

7. The ECD 5100 Data Logger was turned on to monitor the inlet and exit bulk temperatures of the test fluid. When the two temperatures were nearly equal (within $0.2 \mathrm{~F}$ of each other) and their temperatures did not change, the system was considered to be at steady state conditions. This usually required about two hours.

8. While steady state conditions were being achieved, the flow control valve was adjusted to reach the desired Reynolds number. The determination of the desired flow rate for a pre-selected Reynolds number was an iterative procedure. Once the test fluid temperature was relatively constant, that temperature was entered into the "ETH" computer program (Appendix D) as well as several different flow rates until the flow rate for the pre-selected Reynolds number was determined. This 
flow rate was then entered into the turbine meter calibration program "GPMCALC" (Appendix D), where the desired turbine meter frequency was determined. After steady state conditions were achieved, meaning the data logger and frequency counter readings were constant, the Reynolds number was again checked with the computer programs to see if it was still at the preselected value. If the Reynolds number proved unsatisfactory, the procedure was repeated.

9. The 0-20 inwc differential pressure gauge was then connected (quick disconnect fittings were used for each gauge as well as the manometer) to the pressure tap manifold. Manifold valve No. 1 was then opened to determine the differential pressure from the reference pressure tap to pressure tap No. 1. If the differential pressure was less than five inches of water, the 0-5 inwc gauge was connected. If the differential pressure reading on the 0-5 inwc gauge was less than one inch of water, the 0-1 inwc gauge was connected.

10. Once the needle on the gauge had reached its final value, the reading was recorded. Manifold valve No. 1 was then closed and manifold valve No. 2 was opened. If the differential pressure measured at pressure tap No. 2 was greater than the range of the gauge used for pressure tap No. 1 then the 
next higher range gauge (or manometer) was then connected. Again, once the needle on the gauge had reached its final value, the reading was recorded. This procedure was repeated successively with pressure taps Nos. 1 through 20.

11. Several runs were made to obtain averages for the differential pressures at each station ( 1 through 20). This procedure is explained further in the section of this chapter on data reduction.

12. The pump was shut off.

13. The data logger was turned off.

14. The entrance and exit valves to the pressure drop test section were closed.

Some of the Problems Encountered

The quick-disconnect fitting that were used to connect the differential pressure gauges and manometer to the pressure tap manifold caused air bubbles to appear in the lines after repeated connecting and disconnecting. This problem was solved by using air bleed valves on the differential pressure gauges. Whenever air bubbles would appear the bleed valves were opened until the bubbles were out of the lines. When air bubbles appeared in the manometer lines, the lines had to be removed from the manometer and re-filled with test fluid.

As the flow rate was decreased in order to attain lower Reynolds numbers, the response time of the differential 
pressure gauges grew increasingly longer. This was caused by the lack of system pressure on the gauges themselves. At flow rates near 1.5 gallons per minute, the response time of the gauges was approximately ten minutes. At flow rates below 1.5 gallons per minute the response time was great enough to render pressure drop measurements in this range unfeasible. No problems were encountered with the response time of the mercury manometer.

Data Reduction

In order to calculate the Reynolds number and skin friction coefficients for different flow rates a computer program was developed to calculate the thermophysical properties of ethylene glycol-water solutions. The computer program, "ETH", utilizes the correlations developed by Bohn, et.al.(1984) for density, absolute viscosity, thermal conductivity, and Prandtl number of ethylene glycol-water solutions. From these properties the program also calculates secondary properties, properties that are calculated from the properties that have correlations, such as coefficient of thermal expansion, kinematic viscosity, specific heat, and thermal diffusivity. The program prompts the user for the mass concentration of ethylene glycol ( 0 for pure water and 1 for pure ethylene glycol), volume flow rate, average bulk temperature, wall temperature, and tube diameter. From this information the program calculates the thermophysical properties as well as an average fluid velocity, Reynolds 
number, and Grashof number. A listing of the "ETH" computer program is given in Appendix D. A listing of the correlations and a comparison of the calculated thermophysical properties with other sources is given in Appendix $\mathrm{E}$.

An extension of the "ETH" computer program was developed to calculate apparent friction factors from the measured differential pressures. This program was called "FFC", Friction Factor Calculations, and is listed in Appendix D. Once the "ETH" program had been executed, the values for Reynolds number, average fluid velocity, and density were sent to "FFC". The $x / D$ ratios for each pressure tap location are stored in the program. Therefore, the only inputs in the "FFC" program were the last pressure tap. station read in inches of water and the average differential pressure (either in. of water or in. of $\mathrm{Hg}$ ) between the reference pressure tap and each pressure tap location. The apparent friction factors were then calculated with Equation (1.2). For the purpose of calculating apparent friction factors the term "L" refers to the tube length between the reference pressure tap and the pressure tap station over which the differential pressure was measured.

In order to calculate the apparent Eriction factors and the fully developed skin friction coefficients the following procedure was used. Once a steady state was achieved the pressure drops for stations 1 through 18 and station 20 (station 19 was used as a vent) were recorded and the 
procedure was repeated three additional times. The four pressure drops for each station were then averaged. These nineteen average pressure drops were then reduced to apparent friction factors using the "FFC" computer program

The procedure for reducing the data to fully developed skin friction coefficients is as follows. The average pressure drop from the reference pressure tap to station 14 was subtracted form the average pressure drop from the reference pressure tap to station 20 . The procedure was repeated for stations 15, 16, 17, and 18. The pressure tap stations 1 through 13 were not used for the fully developed skin friction coefficient calculations so as to avoid any possible entrance effects. These fully developed pressure drops and their respective tube lengths as well as the density and average velocity of the test fluid were entered into Equation (2.1). From this information, five fully developed skin friction coefficients were calculated for a given Reynolds number. Of these five fully developed skin friction coefficients, the highest and lowest values were discarded and the remaining three were averaged. This average value was taken as the fully developed friction factor for the given Reynolds number. The same procedure was used for the laminar, transition, and turbulent flow regimes. The reader is referred to Appendix $B$ for a sample calculation illustrating this procedure. 
CHAPTER II I

\section{RESULTS AND DISCUSSION}

In order to study fully developed skin friction coefficients in the transition flow regime, apparent and fully developed friction factors in the well established laminar and turbulent flow regimes were experimentally obtained. The spectrum of Reynolds numbers covered throughout the study ranged from 512 to 14970. By covering a large range of Reynolds numbers the validity of the experimental setup could be verified with the established correlations and entrance effects in the established flow regimes could aid in predicting the behavior of the transition flow regime. A listing of the Reynolds numbers covered, their respective fully developed skin friction coefficients and the test fluid concentration used in obtaining them is included as Table II. The source for all of the data obtained in the study is listed in Appendix $A$.

\section{Moody Diagram}

The data, listed in Table II, is plotted as a Moody diagram in Figure 3.1. The method for obtaining these fully developed skin friction coefficients is described in Chapter I . From the Moody diagram it can be seen that the data 
TABLE I I

FULLY DEVELOPED SKIN FRICTION COEFFICIENTS AND THE FLUID CONCENTRATIONS USED TO OBTAIN THEM

$100 \%$ Ethylene Glycol

Re $\quad \mathrm{C}=$

$\begin{array}{rl}512 & 0.0320 \\ 979 & 0.0165 \\ 1520 & 0.0104 \\ 1685 & 0.00930 \\ 1860 & 0.00838\end{array}$

$60 \%$ Ethylene Glycol

$\begin{array}{llll}\operatorname{Re} & C= & \operatorname{Re} & C \pm \\ 2055 & 0.00740 & 2610 & 0.0104 \\ 2090 & 0.00745 & 2710 & 0.0106 \\ 2120 & 0.00815 & 2800 & 0.01075 \\ 2150 & 0.00856 & 2980 & 0.0108 \\ 2195 & 0.00888 & 3140 & 0.01075 \\ 2310 & 0.00940 & 3460 & 0.0107 \\ 2390 & 0.00949 & 3690 & 0.0105 \\ 2450 & 0.00980 & 4400 & 0.00973 \\ 2510 & 0.0101 & 4620 & 0.00955\end{array}$

$100 \%$ Distilled Water

$\operatorname{Re}$

5080

5970

6990

8980

10000
C $=$

0.00913

0.00927

0.00858

0.00808

0.00785
Re

11030

12020

13030

14350

14970
$C=$

0.00753

0.00720

0.00713

0.00708

0.00698 
follows the laminar skin friction coefficient line closely until Reynolds numbers of slightly greater than 2000 . At this point the onset of transition is seen to occur. The fully developed skin friction coefficients begin to increase in a parabolic manner until they reach the turbulent skin friction coefficient line. At Reynolds numbers greater than 3000 the data begins to closely follow the turbulent skin friction coefficient line. A plot of the percent deviation of the experimental data from the fully developed laminar skin friction coefficient correlation in the laminar region $(512<\operatorname{Re}<1980)$ is included as Figure 3.2. The percent deviation in the laminar region ranged from $2.1 \%$ to $-2.7 \%$ which was considered to be well within the tolerance of the system. The uncertainty analysis performed for the data obtained in this study is shown in Appendix $\mathrm{C}$ and shows the maximum probable error in the data to be $+5.23 \%$. A plot of the percent deviation of the experimental data from the Blasius fully developed skin friction coefficient correlation in the turbulent region $(2980<\mathrm{Re}<14970)$ is included as Figure 3.3. The percent deviation in the turbulent region ranged from $3.5 \%$ to $-5.0 \%$ which is within the accuracy of the experimental data.

Table I, listed in Chapter I, lists other turbulent flow friction factor correlations by Bhatti \& Shah and Drew et al. but in the range of turbulent Reynolds numbers used in this study these correlations differed from the Blasius correlation by less than $1 \%$. It is for this reason that the 




Figure 3.1 Moody Diagram 




Figure 3.2 Percent Deviation from the Laminar Skin Friction Coefficient 


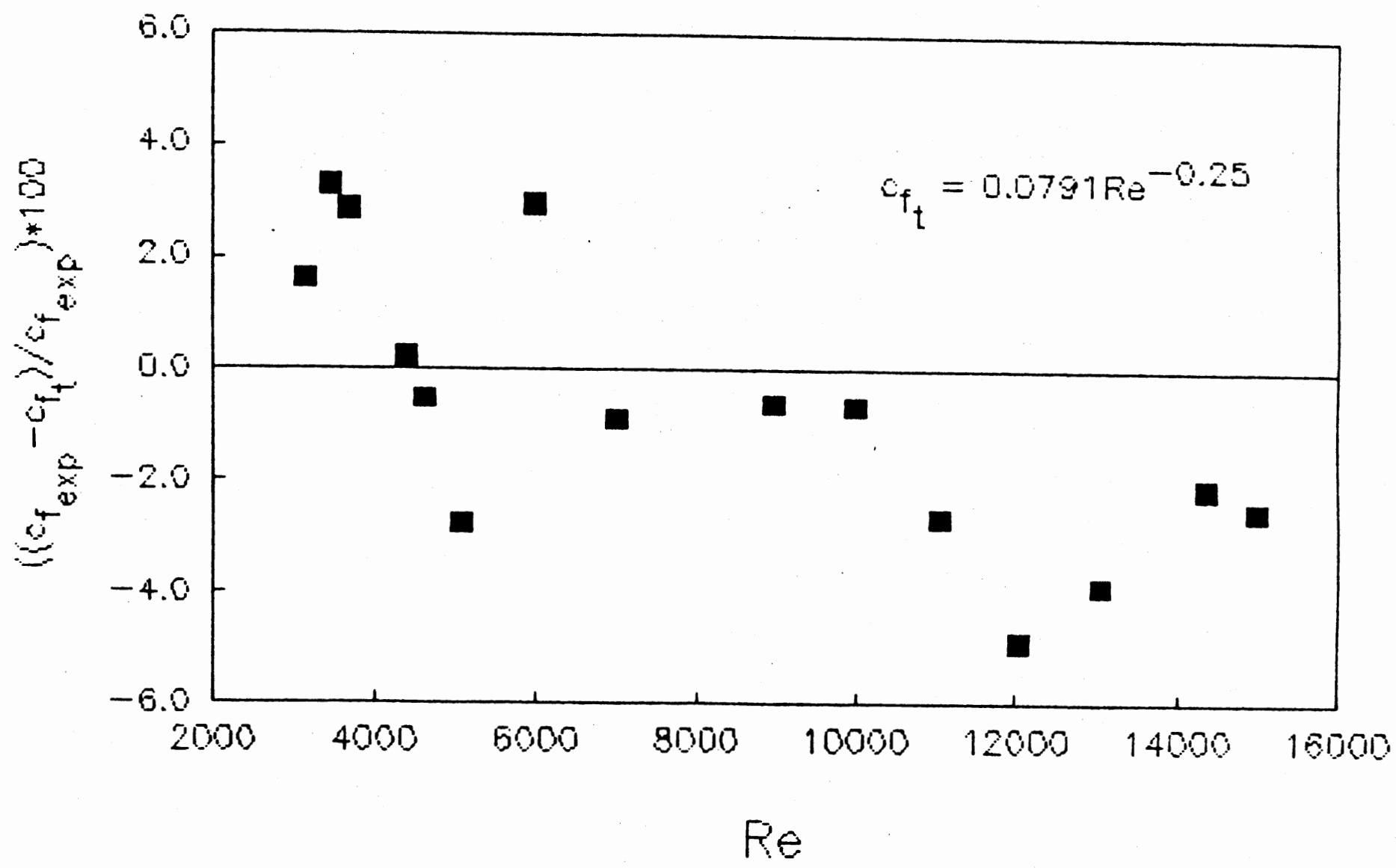

Figure 3.3 Percent Deviation from the Turbulent Skin Friction Coefficient 
experimental data was not compared to them.

Transition Region

A magnified version of Figure 3.1 is included as Figure 3.4. This was done to isolate the transition region so its trends could be seen more clearly. Also included in Figure 3.4 are plots of transition region fully developed skin friction coefficient correlations by Churchill (1977), Hrycak \& Andruskriw (1974), and Bhatti \& Shah (1987). These correlations are listed in Table I. It can be seen that the experimental data shows the transition region occurring sooner (i.e. at a lower Reynolds number) and lasting for a smaller range of Reynolds numbers than the three correlations predict. This is where the effect of the highly disturbing square-edged entrance can be seen. The transition from laminar to transition flow was determined to occur at a Reynolds number of 2070. Transition flow developed into Eully turbulent flow at a Reynolds number of 2840 . Therefore, based solely on a fully developed skin friction coefficient the Blasius correlation was deemed accurate at Reynolds number as low as 2840 for this particular entrance in association with a smooth round tube. A rounded entrance or short bell mouth entrance was used in the development of the three established correlations. As predicted, the square-edged entrance produces a quicker transition and a higher degree of transition than a rounded entrance thus bringing about a fully developed turbulent flow at a lower 


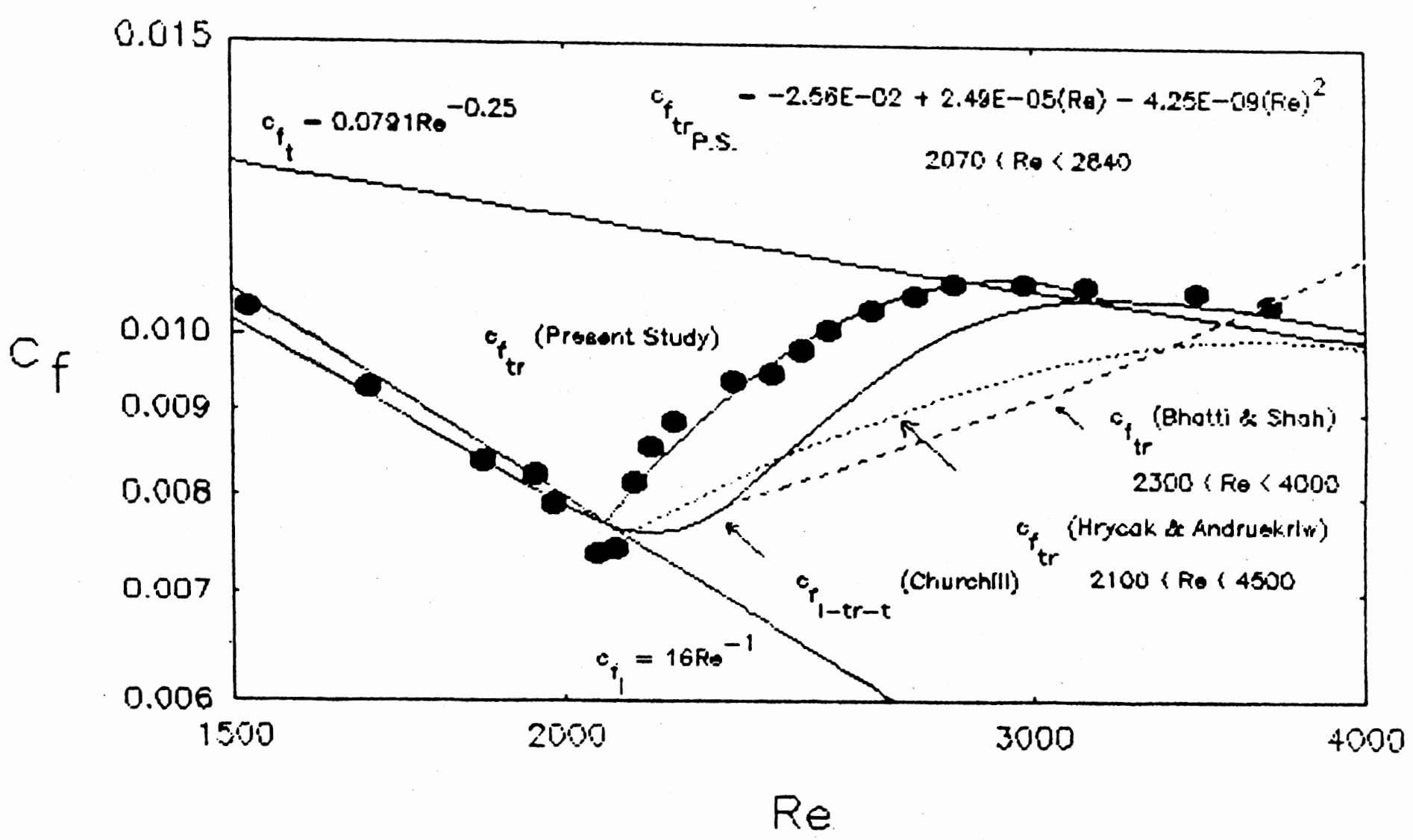

Figure 3.4 Moody Diagram of the Transition Region 
Reynolds number. Since the data in the transition region was parabolic in nature the data was fit with a second order polynomial using the least squares method. The resulting correlation and its applicable range are listed below.

$$
\begin{gathered}
C \text { ete }=-2.56 E-2+2.49 E-5(\operatorname{Re})-4.25 E-9(\operatorname{Re})^{2} \\
2070<\operatorname{Re}<2840
\end{gathered}
$$

The percent deviation of the fourteen transition flow data points from the equation ranged from $4.08 \%$ to $-4.91 \%$ with an average absolute percent deviation from the fit of $1.90 \%$.

The second order polynomial was set equal to the laminar skin friction coefficient equation and a Reynolds number was solved for iteratively. The same was done with the Blasius correlation. This resulted in a range of Reynolds numbers, $2070<\operatorname{Re}<2840$, where a fully developed skin friction coefficient could be predicted with the polynomial. The Reynolds numbers used in the curve fit ranged from 2055 to 3140. This was done to provide a more continuous set of data from which to fit a polynomial.

The parabolic nature of the fully developed skin friction coefficients in the transition region agrees well with the works of Ogawa \& Kawamura (1987) and Senecal \& Rothfus (1953). Also using a smooth round tube with a square-edged entrance senecal and Rothfus determined the transition region to be $2100<\operatorname{Re}<2800$. Their work is supported with pressure drop measurements and velocity profile measurements. Using a similar type entrance, ogawa \& 
Kawamura reported the transition region to be $2000<\operatorname{Re}<3000$. Their work is supported with pressure drop measurements only. Both of these works report data for the fully developed region only, they report no data for the entrance region. However, this study includes entrance region information to augment that of the fully developed region. It is important to note that air was used as a test fluid in the works of Ogawa \& Kawamura and Senecal \& Rothfus. By using liquids as a test fluid the data from this study helps to confirm and improve upon the results of the previously mentioned authors because of the different type of fluid used.

A plot of the percent differences between the experimental data and the derived correlation, Churchill's, Hrycak \& Andruskriw's, and Bhatti \& Shah's correlations is included as Figure 3.5. It should be noted that Hrycak \& Andruskriw's correlation is also a second order polynomial. However, their correlation predicts transition flow to begin at a Reynolds number of 2100 and end at a Reynolds number of 4500. Churchill's range of Reynolds numbers for the transition region can visually be determined to be between Re $=2100$ and $R e=3200$. This differs from the correlation presented in this study because the disturbing nature of the square-edged entrance used in this study causes transition to start earlier and last for a smaller range of Reynolds numbers. It is for this same reason that transition is predicted earlier than it is for Churchill's correlation. 




Figure 3.5 Percent Deviation from the Transition Skin Friction Coefficients 
Churchill's correlation is not parabolic in nature because it is a model that continuously predicts fully developed friction factors in the laminar, transition, and turbulent flow regimes. Bhatti \& Shah's correlation shows a different trend than does the data therefore its use is not recommended for circular tubes with a square-edged entrance. The correlation is not parabolic in nature and produces a sharp interface with turbulent line thus predicting a discontinuity from transition to turbulent flow. This study and others do not predict such discontinuities.

\section{Length Required for a Fully Developed \\ Friction Factor}

To further support the experimentally determined early onset of transition flow, two figures are included showing the apparent friction factors for laminar flow. Figure 3.6 displays apparent friction factor ( $f_{m p}$ ) versus the dimensionless axial location of the pressure taps ( $x / D$ ) for five separate Reynolds numbers in the laminar range. It can be seen from this figure that as the Reynolds number increases the tube length required for the apparent friction factor to become constant decreases. For example; at a Reynolds number of 512 the friction factor becomes constant near 100 diameters, at a Reynolds number of 1860 the friction factor becomes constant near 60 diameters.

Figure 3.7 displays the same data in the form used by Langhaar (1942) with the apparent friction factor multiplied 


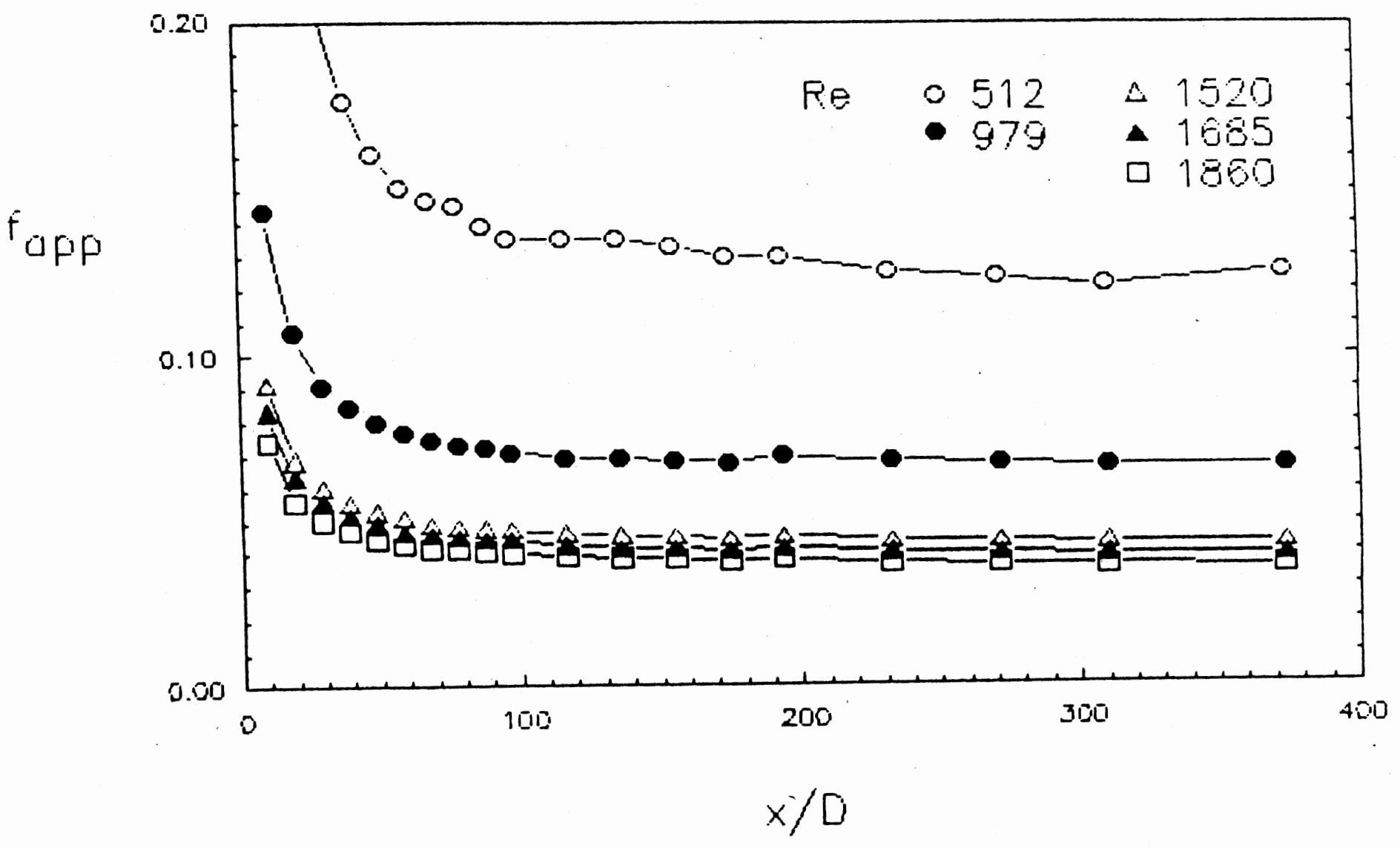

Figure 3.6 Laminar Flow Apparent Friction Factors 


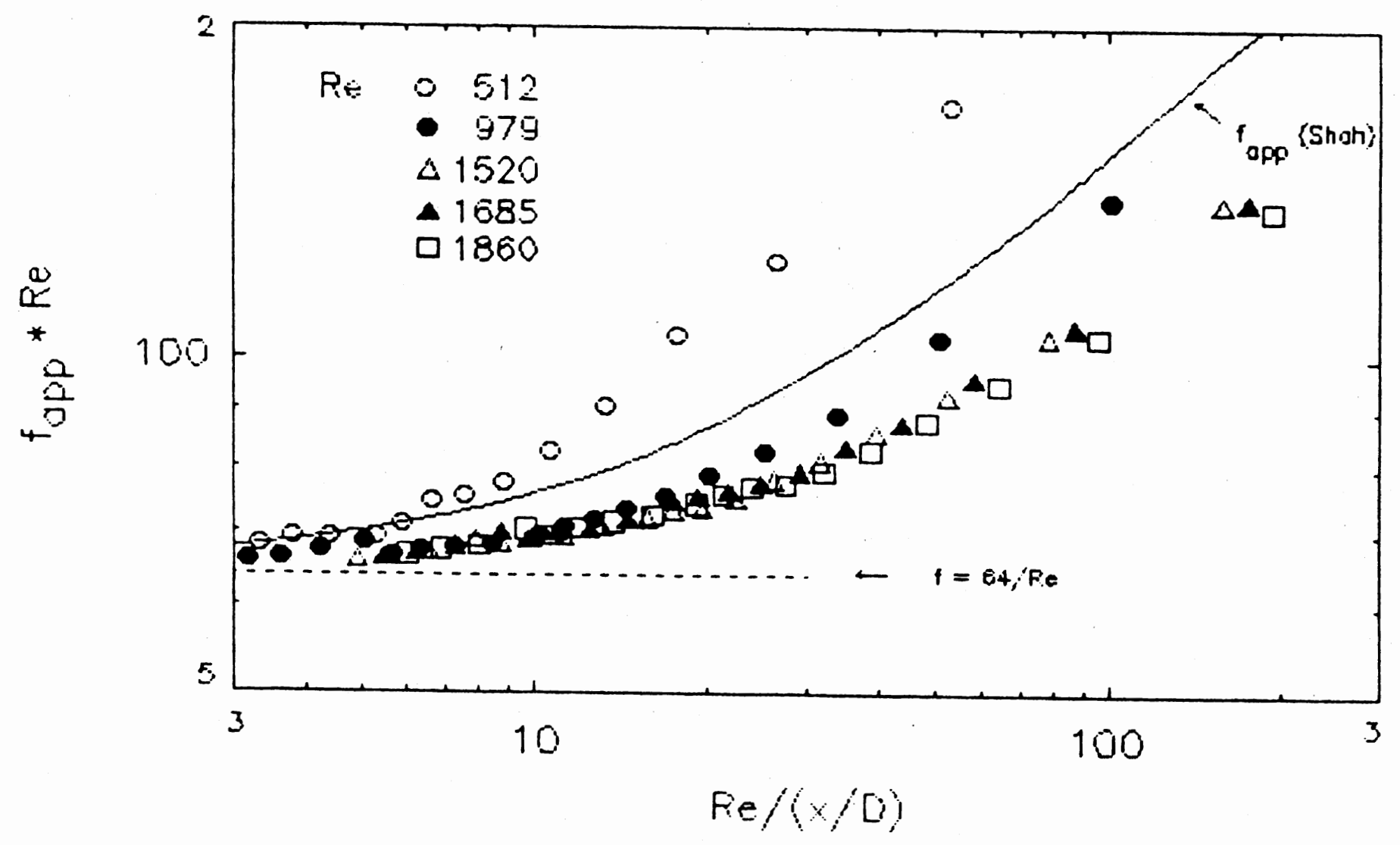

Figure 3.7 Laminar Friction Factors in the Entrance Region 
by the Reynolds number versus the Reynolds number divided by the dimensionless axial distance. Figure 3.7 also shows a plot of the equation reported by Shah (1977), listed in Table I, which is based on the theory of Langhaar. Langhaar's theory for the hydrodynamic entry length for laminar flow in smooth round tubes is based on a short bell-mouthed entrance configuration as opposed to the square-edged entrance used for this study. It can be seen that the data approaches the line of $\mathrm{f}=64 / \mathrm{Re}$ as expected. However, the data is shifted to the right of the line predicted by shah thus predicting a shorter hydrodynamic entry length than shah. It should be noted that the term "hydrodynamic entrance length" refers to the length required to fully develop the velocity profile. However, in this study the hydrodynamic entrance length is being compared to the tube length required for the friction factor to become constant. It should also be noted that in Langhaar's work the apparent friction factor line never reaches the $\mathrm{f}=64 / \mathrm{Re}$ line but the friction factor line does. This is supported by the data because the data remains slightly above the $f=64 / \operatorname{Re} 1$ ine.

Although no velocity profile measurements were made and the flow visualization study has yet to be completed it is the author's intuition that states the square-edged entrance used in this study causes the laminar boundary layer to grow faster than a bell-mouthed entrance does thereby providing a shorter length required for the friction factor to become constant. By using shah's correlation for a circular tube 
with a square-edged entrance one could be in error by $-34 \%$ to $57 \%$ in extreme cases, such as predicting apparent friction factors near the inlet of a tube. The experimental data begins to agree with shah's correlation at $\mathrm{Re} /(\mathrm{x} / \mathrm{D})$ values less than 10 .

It is assumed that since the inlet configuration has a significant impact on the development of the laminar boundary layer it must also have an impact on the range of Reynolds numbers where transition flow occurs.

Figure 3.8 , a figure similar to that of Figure 3.6 for laminar flow, is included for fully turbulent Reynolds numbers ranging from 5080 to 14970 . From these plots of turbulent apparent friction factors a correlation was developed to predict the turbulent entrance length of flows with Reynolds numbers ranging from 5000 to 15000 . The correlation that was developed is solely based on a fully developed friction factor as opposed to being based on the development of the velocity profile as was done by Latsko (1921) and white (1986), reported by white. The data for the turbulent entrance length correlation was obtained by inspection of Figure 3.8 and visually determining the pressure tap station where the apparent friction factor became constant. Thus eleven data points were obtained and curve fit was performed using the least squares method. This data and the corresponding correlation appear on Figure 3.9 . The eleven data points used had an absolute average percent deviation from fit of $9.56 \%$ and maximum of $14.9 \%$. The 


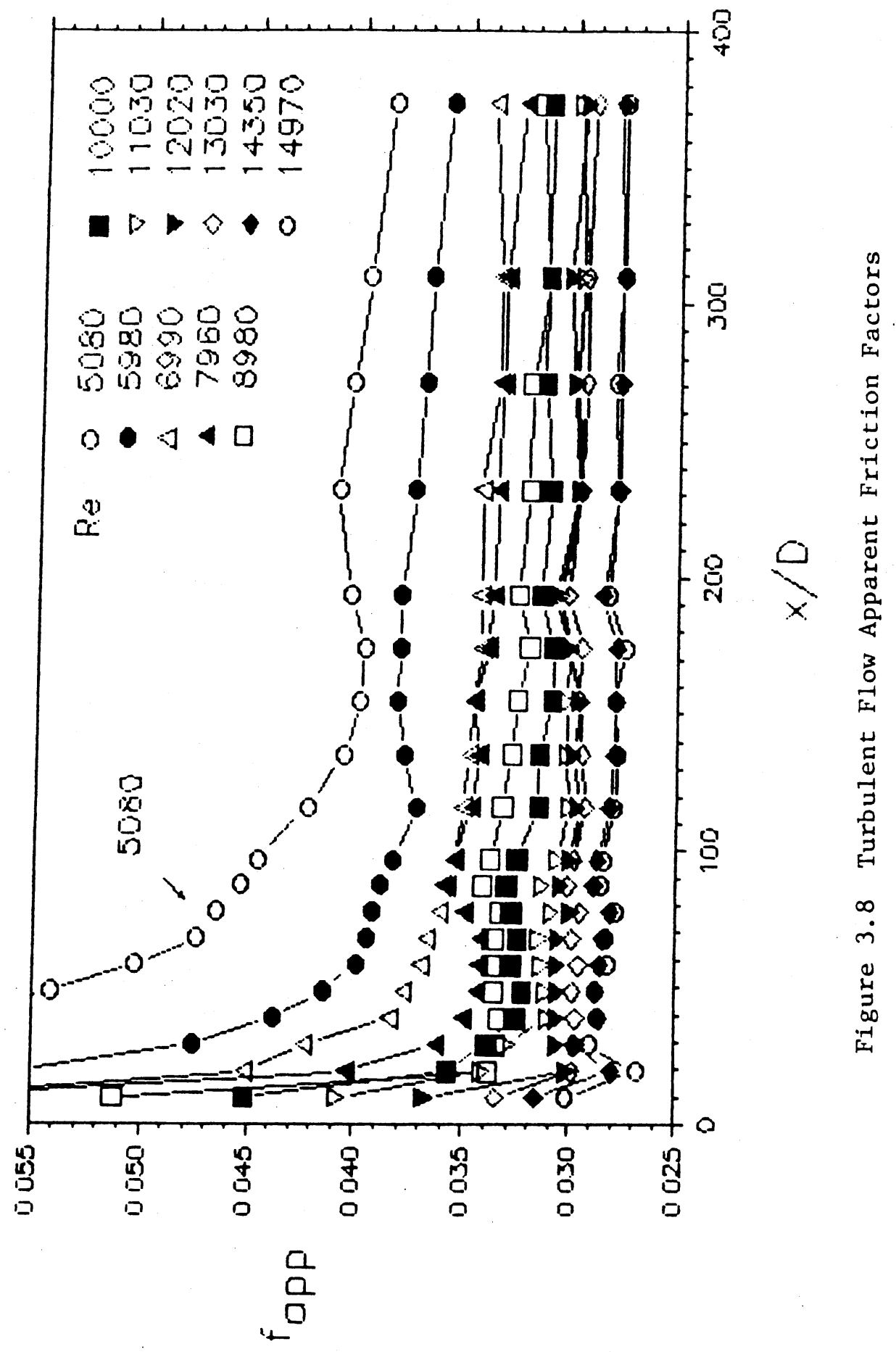




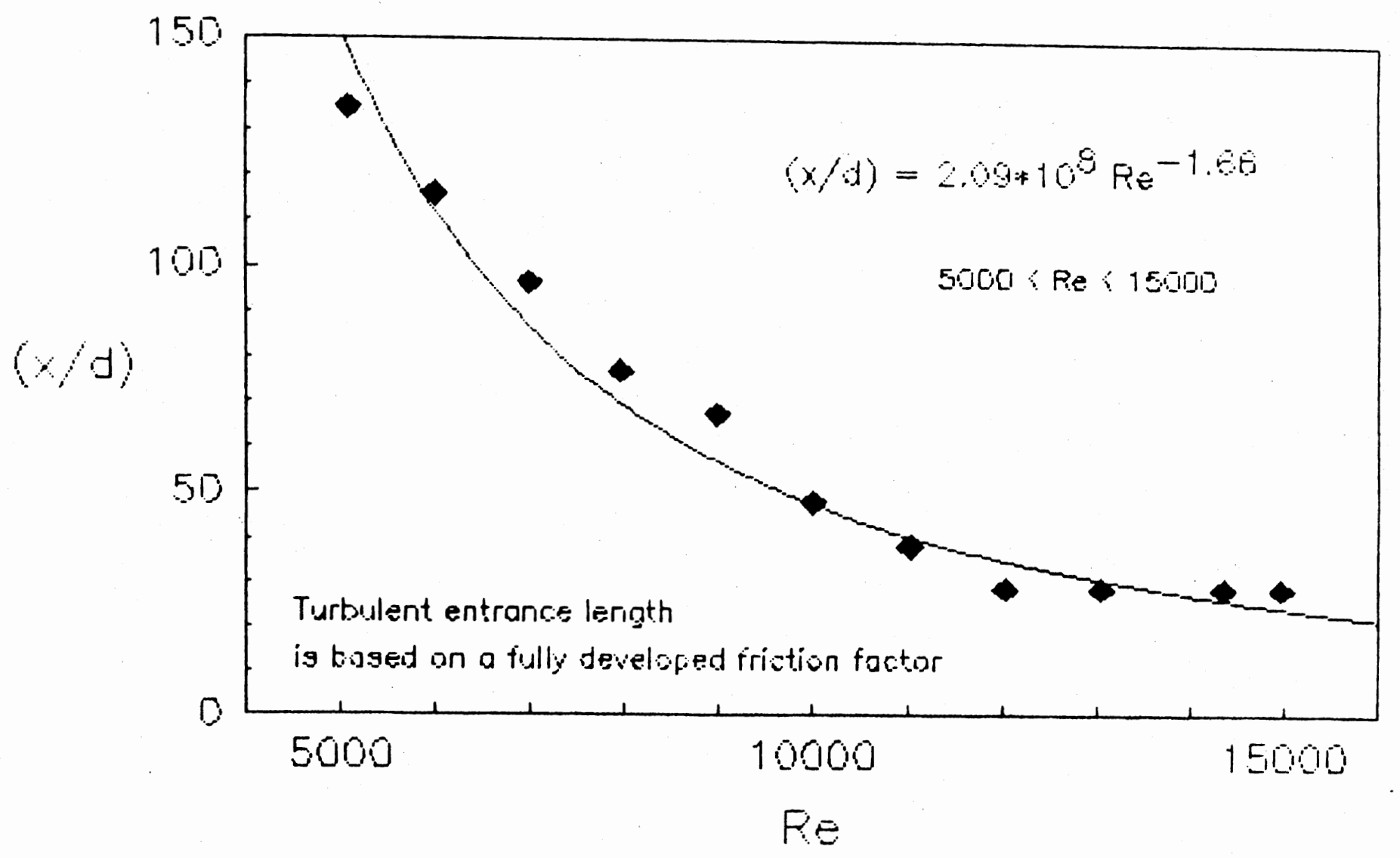

Figure 3.9. Turbulent Entrance Length 
maximum probable error in the data was $5.23 \%$. It can be seen that the tube length required for the friction factor to become constant is inversely proportional to Reynolds number. This is exactly the opposite trend that correlations for the hydrodynamic entrance length predict. However, this is the same trend that appears on the plot of the laminar apparent friction factors, Figure 3.6. This is due to the fact that as the Reynolds number increases the skin friction between the fluid and the tube wall plays an increasing role in the pressure drop and begins to overshadow the role in the pressure drop played by the development of the velocity profile. The data shows that after Reynolds numbers greater than 20000 the flow can be considered fully developed turbulent flow at the entrance for the purpose of friction factor determinations. The author recommends the correlation stated in Figure 3.9 as a means of making an approximation as to how many diameters down a tube the fully developed friction factor correlations become valid for a smooth round tube with a square edged entrance. For example, at a Reynolds number of 10000 the friction factor would become constant near 50 diameters. A similar correlation was not developed for the laminar flow regime because the laminar flow data did not show as strong a trend as the turbulent data did. 
CHAPTER IV

SUMMARY, CONCLUSIONS, AND RECOMMENDATIONS

In the previous chapter experimental data for pressure drop measurements in three fluid flow regimes (laminar, transition, and turbulent) in a smooth round tube with a square-edged entrance were presented. This chapter presents the accomplishments of the present study and gives recommendations for future study in this area.

\section{Summary}

A versatile experimental setup was constructed so that further research could be performed to determine the effects of different inlet configurations and the effects of a constant wall heat flux condition on the skin friction coefficient in the transition flow regime. The experimental setup also has the versatility to allow intermittency measurements to be made.

In order to cover the three flow regimes the range of Reynolds numbers covered was 512 to 14970 . From this range of Reynolds numbers thirty three fully developed skin friction coefficients were obtained. These values are listed in Table II and displayed in Figure 3.1. The experimental data agreed quite well with the established correlations for fully developed laminar and turbulent skin friction 
coefficlents.

It was at a Reynolds number of 2070 where the fully developed skin friction coefficients began to deviate from the laminar line thus showing the onset of transition flow. The critical Reynolds number is slightly lower than those reported by other researchers because of the disturbing nature of the square-edged entrance used in this study. The fully developed skin friction coefficients in the transition region increased in a parabolic nature until they reached the turbulent line at a Reynolds number of 2840 . The reader is referred back to Figure 3.4 to review the trends of the data reported compared with those of the correlation reported in the literature. The second order polynomial used to fit the data in the transition region and its applicable range is

$$
\begin{gathered}
C=-2.56 \mathrm{E}-2+2.49 \mathrm{E}-5(\operatorname{Re})-4.25 \mathrm{E}-9(\mathrm{Re})^{2} \\
2070<\operatorname{Re}<2840
\end{gathered}
$$

This correlation fits the data with an average absolute percent deviation from fit of $1.90 \%$ and maximum absolute percent deviation from fit of 4.91\%. In performing the uncertainty analysis, shown in Appendix $C$, it was determined that the maximum probable error in the data was $5.23 \%$.

It is the upper limit of this correlation which expands the range of applicable Reynolds numbers where the Blasius correlation is valid for a smooth round tube with a squareedged entrance. The transition range reported in this study, 
$2070<\operatorname{Re}<2840$, compares well with those reported by Senecal \& Rothfus (1953) for an identical inlet configuration and Ogawa \& Kawamura (1987) for a similar inlet configuration. The transition skin friction coefficient correlation presented in this study is the first of its kind for a circular tube with square-edged entrance and helps to provide additional understanding about the long misunderstood region of transition flow. The correlation developed will be of most use to the heat exchanger industry since smooth round tubes with a square-edged entrance are commonly used in shell and tube heat exchangers.

Also of use to the heat exchanger industry is the correlation developed in this study to predict the turbulent entrance length for flow with Reynolds numbers ranging from 5000 to 15000 .

$$
x / D=2.09 E 8(\operatorname{Re})^{-1.66}
$$

This equation will aid designers in determining how far down a tube the Blasius friction factor becomes valid thus aiding in more accurate pumping power estimates.

For laminar flows in a smooth round tube with a square-edged entrance the tube length required for the friction factor to become constant is also inversely proportional to the Reynolds number. For example; at a Reynolds number of 512 the friction factor becomes constant near 100 diameters, at a Reynolds number of 1860 the friction factor becomes constant near 60 diameters. 
Conclusions

The general conclusions drawn from this study may be summarized as follows:

1. The validity of the versatile experimental setup that was constructed was verified by the close agreement of the experimental data and the established skin friction coefficient correlations for fully developed laminar and turbulent flow. Therefore, the author is confident that pressure drop measurements made with different inlet configurations, under a constant wall heat flux condition, and involving intermittency measurements will provide valuable data.

2. A smooth round tube with a square-edged entrance produces a transition flow regime in the Reynolds number range of $2070<\operatorname{Re}<2840$. When plotted versus Reynolds number, the fully developed friction factors in the transition region are parabolic in nature.

3. The disturbing nature of the square-edged entrance is believed to cause the laminar boundary layer to grow faster thus resulting in shorter tube length required for the skin friction coefficient to become constant than predicted by the established correlation for a short bell-mouthed entrance in laminar flow. 
4. The tube length required for the skin friction coefficient to become constant in the turbulent region with Reynolds numbers ranging from 5000 to 15000 is inversely proportional to the Reynolds number based solely on a fully developed skin friction coefficient. For Reynolds numbers greater than 20000 in smooth round tube with a square-edged entrance the flow can be considered fully developed at the entrance for the purpose of making pressure drop calculations.

\section{Recommendations}

The following recommendations made for future studies of this type are based on the observations made during this study.

1. Improvements can be made in performing pressure drop measurements of this type when a differential pressure transducers for liquids having differential pressures in the zero to fifty inwc range are developed. The differential pressure tranducers should be accurate to 0.01 inwc in order to make a significant improvement upon this study. The transducers would also probably have a much quicker response time than differential pressure gauges thereby allowing more data to be obtained.

2. It has been proven by other researchers that the Reynolds number range for transition flow is a 
strong function of the inlet configuration. Other inlet configurations (such as bell-mouth and re-entrant inlet configurations) need to be studied to determine what effects they have on the transition region in smooth round tubes and the effects they have on the the tube length required to reach a fully developed friction factor.

3. Friction factors in the transition region under a constant wall heat flux condition need to be studied to determine what affect the induced heat flux has on inducing transition flow and to see if the transition region remains in the same range of Reynolds numbers for the same inlet. This type of study would also aid heat exchanger designers in predicting pumping power requirements. studying transition flow friction factors for different inlets under a constant wall heat flux condition would further augment the work that has been done.

4. Introducing the concept of intermittency into the measurements already made and into future measurements could provide further validation of the transition range previously determined in this study. Intermittency measurements could also be introduced into the correlations developed in this study to determine if they compare well to those developed by Ogawa and Kawamura (1987). 
REFERENCES 
Benedict, R. P. (1984). Eundamentals of Temperature, Pressure, and Flow Measurements. John wiley \& Sons, New York.

Bhatti, M. S. and Shah, R. K. (1987). Handbook of single-Phase convective Heat Transfer, John wiley \& Sons, New York.

Bohn, D., Fischer, S., and oberme1r, E. (1984). Thermal Conductivity, Density, Viscosity, and Prandtl Numbers of Ethylene Glycol-water Mixtures. Ber. Bunsenges. Phys. Chem. Vol. 88, pp. 739-742.

Churchill, S. W. (1977). Comprehensive Correlating Equations for Heat, Mass and Momentum Transfer in Fully Developed Flow in Smooth Tubes. Ind. Eng, Chem. Fundam. Vol. 16, pp. 109-116.

Hrycak, P. and Andrushkiw, R. (1974). Calculation of Critical Reynolds Number in Round Pipes and Infinite Channels and Heat Transfer in Transition Regions. Heat Transfer. Vol. II, pp. 183-187.

Langhaar, H. L. (1942). steady Flow in the Transition Length of a straight Tube. Journal of Applied Mechanics. Vol. 9, pp. A-55-A-58.

Kline, S. J. and MCClintock, F. A. (1953). Describing Uncertainties in Single sample Experiments. Mechanical Engineering. Vol. 66 , pp. 3-8.

Ogawa N. and Kawamura, H. (1987). Effects of Entrance Configuration on Pressure Loss and Heat Transfer of Transitional Gas Flow in a Circular Tube. Heat Transfer Japanese Research. Vol. 7, pp. 77-91.

Senecal, V. E. and Rothfus, R. R. (1953). Transition Flow of Fluids in smooth Tubes. chemical Engineering Progress, Vol. 10 , pp. 533-538.

Shah, R. K. (1978). A Correlation for Laminar Hydrodynamic Entry Length Solutions for Circular and Noncircular Ducts. Journal of Fluids Engineering.

Shapiro, A. H. and Smith, R. D. (1957). Friction Coefficients in the Inlet Length of Smooth, Round Tubes. NACA. TN No. 1785, pp. 1-43.

Strickland, D. T. (1990). Heat Transfer Measurements in the Transition Region for a Circular Tube with a SquareEdged Entrance. MS Thesis, Oklahoma state University, stillwater, Oklahoma. 
White, F. M. (1986). Eluid Mechanics, McGraw Hill, New York. 


\section{APPENDI XES}


APPENDIX A

DATA SOURCE 
DATA SOURCE

The data for this study is available through

Dr. Afshin J. Ghajar

Asscociate Professor of Mechanical Engineering

School of Mechanical and Aerospace Engineering

Oklahoma state University

218 Engineering North

stillwater, OK 74078

405-744-5900 
APPENDIX B

SAMPLE CALCULATION 


\section{SAMPLE CALCULATION}

The following sample calculation illustrates the procedure used to calculate a fully developed skin friction coefficient. The data used is that taken using distilled water at a Reynolds number of 6990.

After obtaining the average pressure drops using the procedure outlined in Chapter II, the average pressure drop from station fourteen is subtracted from the average pressure drop from station twenty. This procedure is repeated for stations fifteen through eighteen.

$$
\begin{aligned}
& \Delta \mathrm{P}_{20-14}=2.0875 \text { inwC } \\
& \Delta \mathrm{P}_{20-1 \mathrm{~S}}=1.8750 \text { inwC } \\
& \Delta \mathrm{P}_{20-10}=1.4625 \text { inwC } \\
& \Delta \mathrm{P}_{20-17}=1.1125 \text { inwC } \\
& \Delta \mathrm{P}_{20-10}=0.7125 \text { inwC }
\end{aligned}
$$

To obtain a skin friction coefficient from the differential pressures equation (B.1) is used.

$$
C_{E}=\frac{(\Delta P)(5.2)\left(D_{1}\right)(g=)}{(1 / 2)(L)\left(V_{\text {avg }}\right)^{2}(\varphi)}
$$

5.2 is the necessary conversion factor to convert inwc to lbf/ft ${ }^{2}$. The gravitational constant, $g=$, is equal to $32.174(1 \mathrm{bm} f t) /\left(1 \mathrm{bf} \mathrm{s}^{2}\right)$. I is equal to the axial distance of the tube over which the pressure drop was measured. Equation (B.2) shows the differential pressure from stations fourteen to twenty and other pertinent data for the 
particular Reynolds number entered into Equation (B.1). $\mathrm{C}=20-24=\frac{2.0875 \mathrm{lnwc} \times 5.2 \mathrm{lbf} / \mathrm{ft}^{2} / \mathrm{inwc} \times 0.05175 \mathrm{ft} \times \mathrm{go}_{0}}{2 \times 10.3021 \mathrm{ft} \times(1.29 \mathrm{ft} / \mathrm{s})^{2} \times 62.11 \mathrm{lbm} / \mathrm{ft}^{3}}$

$C=20-14=0.00849$

Similar calculations are performed to obtained the skin friction coefficients associated with the other pressure tap stations. The only variables that change in Equation (B.1) are the differential pressure, $\Delta P$, and the tube length, $L$.

$C=20-25=0.00845$

$C=20-26=0.00840$

$C=20-17=0.00880$

CE20-12 $=0.00905$

As stated in the section on data reduction, the high and low values are omitted and the remaining three averaged to obtain an average value of the skin friction coefficient for the particular Reynolds number.

$$
C_{x}=0.00858 \text { at } \operatorname{Re}=6990
$$

Since this Reynolds number is in the fully turbulent flow regime it can be compared to the Blasius skin friction coefficient correlation.

$$
\begin{aligned}
C= & =0.0791 \mathrm{Re}-0.25 \\
& =0.0791(6990)-0.25
\end{aligned}
$$


$C=0.00865$

When comparing the two skin friction coefficients it can be seen that the experimental value deviates from the Blasius value by $-0.9 \%$. 
APPENDIX C

UNCERTAINTY ANALYSIS 


\section{UNCERTAINTY ANALYSIS}

The probable error in the experimental measurements of the skin friction coefficient is presented in this appendix. For a complete discussion of the theory of uncertainty analysis see Kline and McClintock (1953).

The skin friction coefficient is defined as

$$
C_{E}=\tau_{w} / \frac{1}{2} \varphi_{f} U^{2}=\left(D_{1} \Delta p / 4 L\right) / \frac{1}{2} \varphi=U^{2}
$$

In terms of the measured quantity it becomes

$$
C==\frac{D_{1} \Delta p g}{2 L \varphi\left[(m x+b) /(\pi / 4) D_{2}^{2}\right]^{2}}
$$

Here, the density of the fluid and the gravitational acceleration are assumed to be accurately known. The procedure for calculating the pressure drop depends upon whether the measurements were made using inches of water or inches of mercury. The term $(m x+b)$ represents a volume flowrate and refers to the turbine meter calibration curves for the three different solutions that were used. This is explained further in the section on data reduction.

The uncertainty in the skin friction coefficient can be found from

$$
\begin{aligned}
\delta C_{ \pm}= & {\left[\left(\partial C_{E} / \partial D_{1}\right) \delta D_{1}\right]^{2}+\left[\left(\partial C_{x} / \partial G\right) \delta G\right]^{2}+\left[\left(\partial C_{x} / \partial H\right) \delta H\right]^{2} } \\
& +\left[\left(\partial C_{x} / \partial L\right) \delta L\right]^{2}+\left[\left(\partial C_{ \pm} / \partial F\right) \delta F\right]^{2} \\
& \left.+\left[\left(\partial C_{ \pm} / \partial T\right) \delta T\right]^{2}\right\}
\end{aligned}
$$

The percentage uncertainty, which can be obtained with the 
substitution of the partial derivatives of Equation (c.3) with respect to each variable into Equation (C.2) and division of its result by Equation (C.3), may be written as

$$
\begin{aligned}
&\left(\delta \mathrm{C}_{2} / \mathrm{C}_{2}\right)(\xi)=100 *\left\{\left(\delta \mathrm{D}_{1} / \mathrm{D}_{1}\right)^{2}+(\delta \mathrm{G} / \mathrm{G})^{2}+(\delta H / H)^{2}+\right. \\
&\left.(\delta \mathrm{L} / \mathrm{L})^{2}+(-\mathrm{mF} /(\mathrm{mF}+\mathrm{b}))^{2}+(\delta \mathrm{T} / \mathrm{T})\right\} \quad(\mathrm{C} .4)
\end{aligned}
$$

The uncertainty of each variable was estimated as follows:

$\delta D_{1}$ : The uncertainty of the inside diameter of the test section was assumed to be $0.002 "$.

$\delta G$ : The accuracy of the differential pressure gauges was given by the manufacturer as $+3 \%$ full scale.

$\delta \mathrm{H}$ : The resolution of the mercury manometer was $+.05 "$ " This value was taken as the uncertainty in $H$.

SL : The pressure tap interval was machined with an accuracy of $+0.002 "$.

$\delta F$ : The reading of the frequency from the turbine meters was influenced by the instantaneous change in flowrate. It was also affected by the calibration procedure. The probable error in $F$ was assumed to be $+2.0 \mathrm{~Hz}$.

$\delta \mathrm{T}$ : The accuracy of the reading of the fluid bulk temperature was assumed to be $+0.5 \mathrm{~F}$.

The following is a sample calculation of the uncertainty in calculating the skin friction coefficient.

$$
\begin{aligned}
& \delta D_{1} / D_{1}=0.002 / 0.621=0.00322 \\
& \delta G / G=0.03
\end{aligned}
$$




$$
\begin{aligned}
& \delta \mathrm{H} / \mathrm{H}=0.05 / 1.47=0.0340 \\
& \delta \mathrm{L} / \mathrm{L}=0.002 / 6.000=0.000333 \\
& \delta F / F=(0.0614 * 2) /(0.0648+0.0614 * 79)=0.0250 \\
& \delta T / T=0.5 / 73.3=0.00682 \\
& \left(\delta C_{\varepsilon} / C_{z}\right)(\xi)=100 *\left\{(0.00322)^{2}+(0.03)^{2}+(0.0340)^{2}\right. \\
& +(0.000333)^{2}+(0.025)^{2} \\
& \left.+(0.00682)^{2}\right\} \\
& \left(\delta C_{\varepsilon} / C_{\varepsilon}\right)(\delta)=5.23 \%
\end{aligned}
$$

Thus the maximum percent probable error in the skin friction coefficient is $5.23 \%$. It can be seen from Equation C.5 that the two greatest influences on the percent probable error are the uncertainty in the differential pressure gauges and the frequency counter reading. 


\section{APPENDIX D \\ COMPUTER PROGRAMS USED IN THE STUDY \\ ETH.BAS \\ FFC. BAS \\ GPMCALC.BAS}




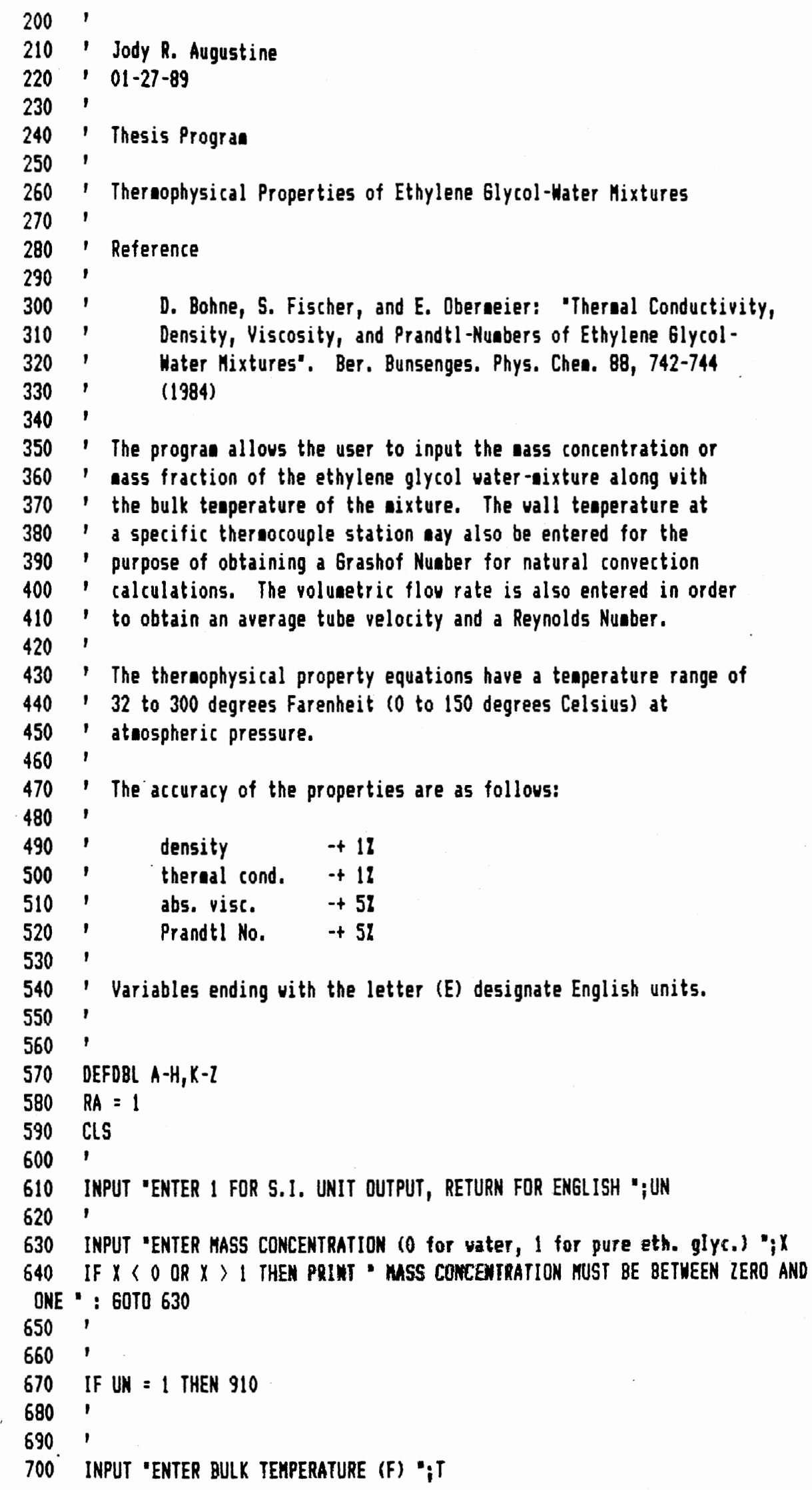


710 IF $T<32$ OR $T>300$ THEN PRINT " BULK TEMPERATURE MUST BE BETWEEN 32 AND

300 DEGREES FARENHEIT' : GOTO 700

720

730 '

740 INPUT 'ENTER NALL TEMPERATURE (F) "iTH

750 IF TW $<=T$ OR TW > 500 THEN PRINT - WALL TEMPERATURE MUST 8E GREATER THAN THE BULK TEMPERATURE AND LESS THAN $500 \mathrm{~F}$ " : GOTO 740

$760 \quad 1$

770 '

780 INPUT 'ENTER FLOHRATE (gpo) ";FL

790 IF FL $<0$ OR FL $>20$ THEN PRINT " FLOHRATE MUST BE BETWEEN O AND 20 gPa" : 60T0 780

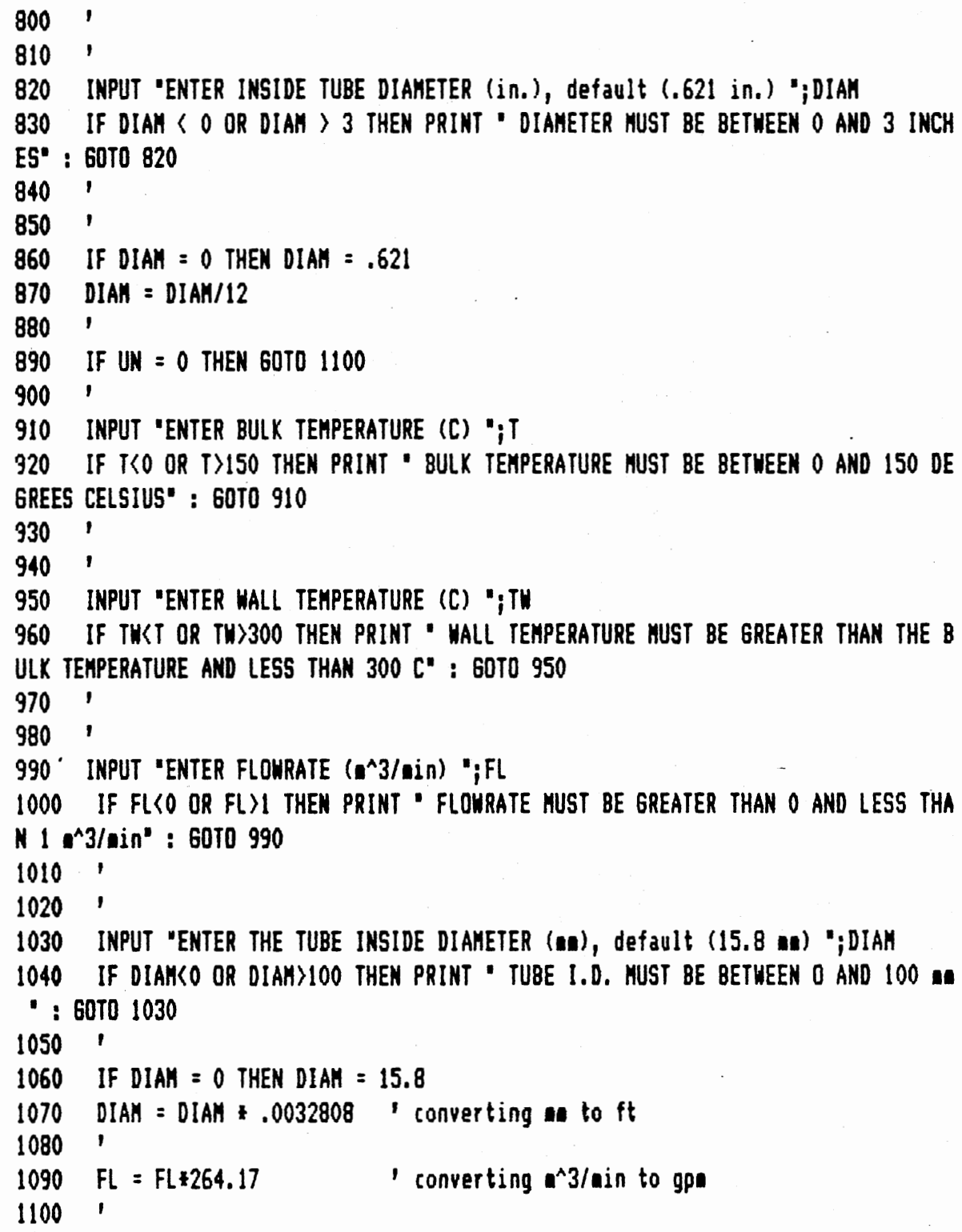




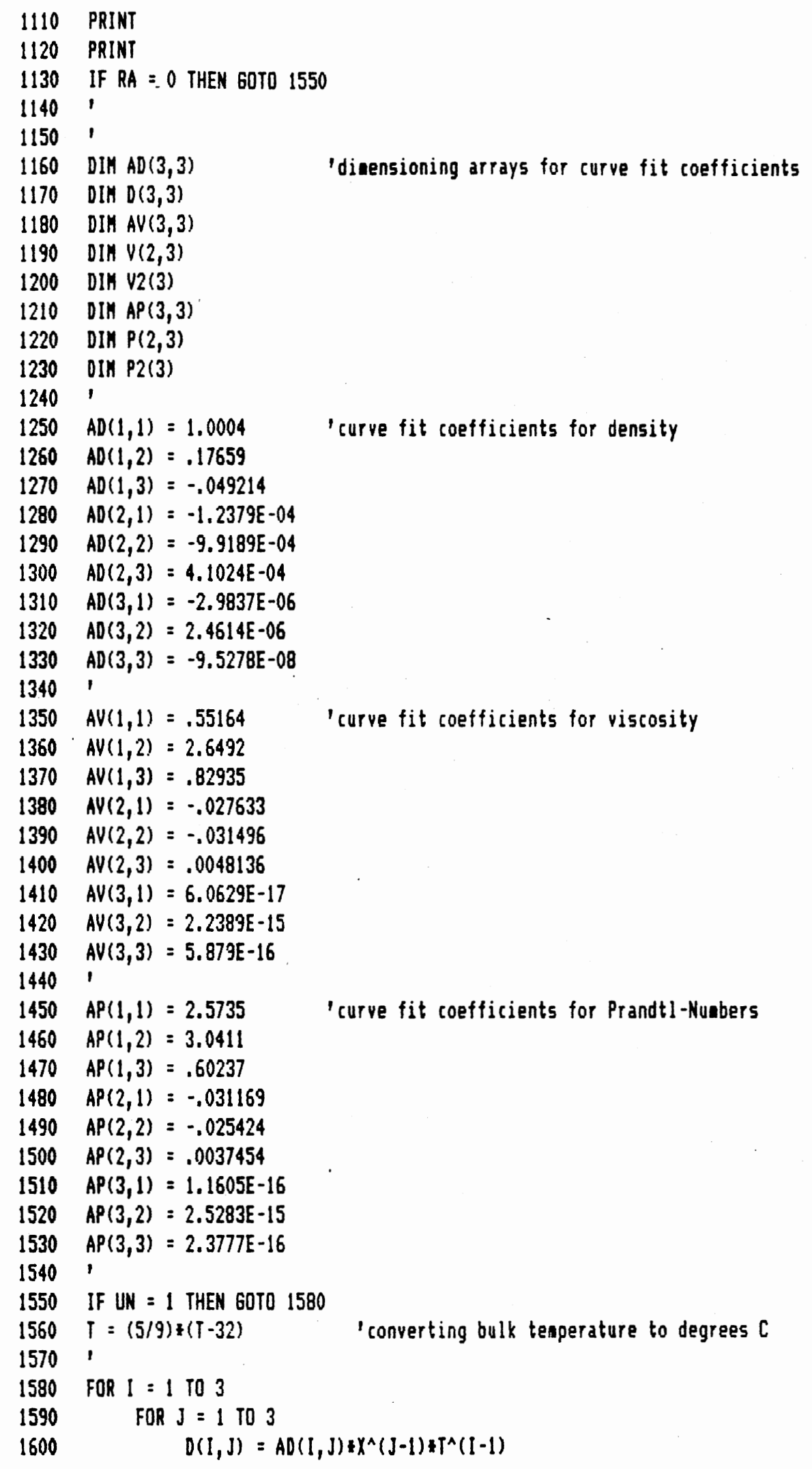




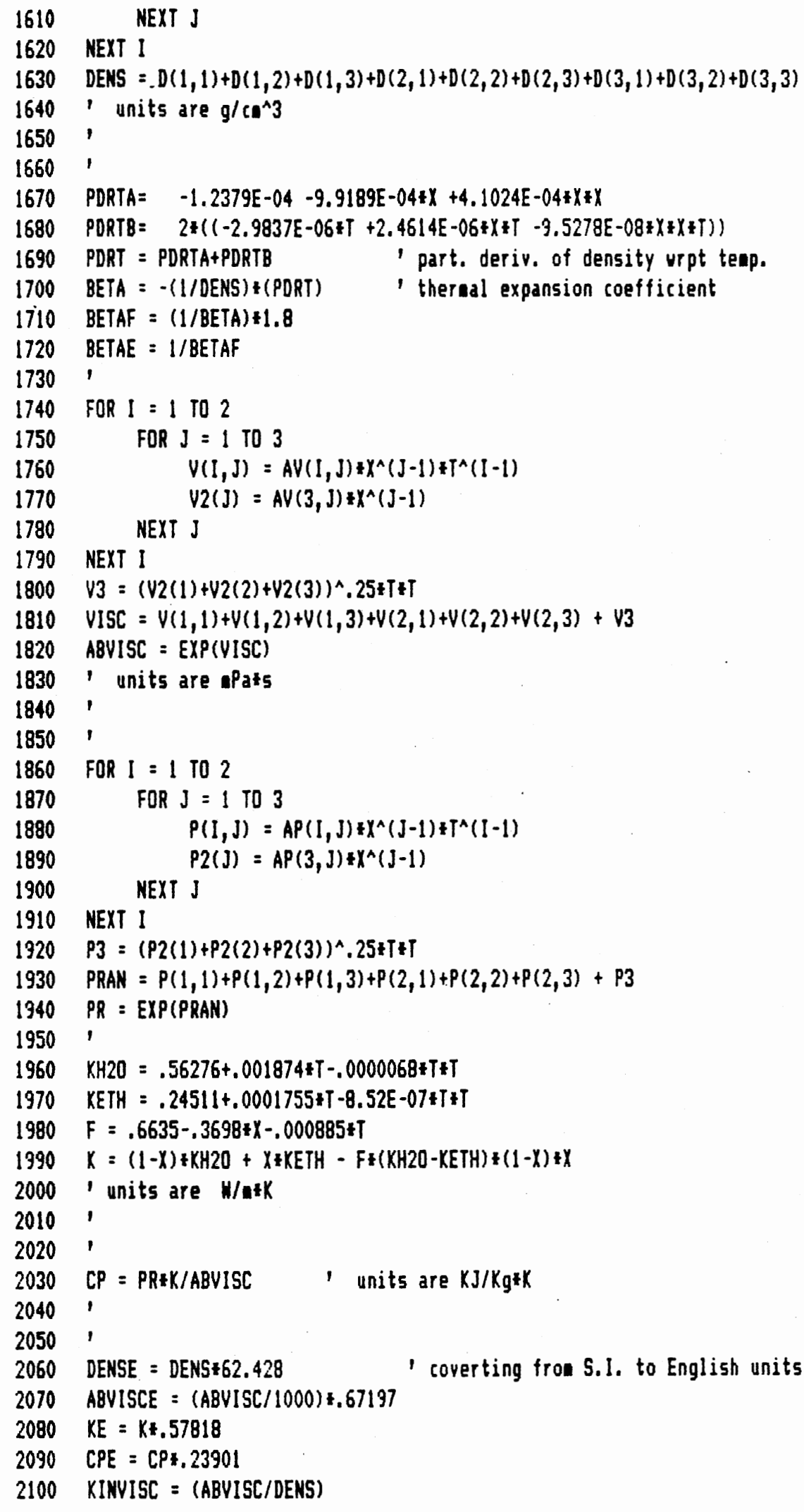




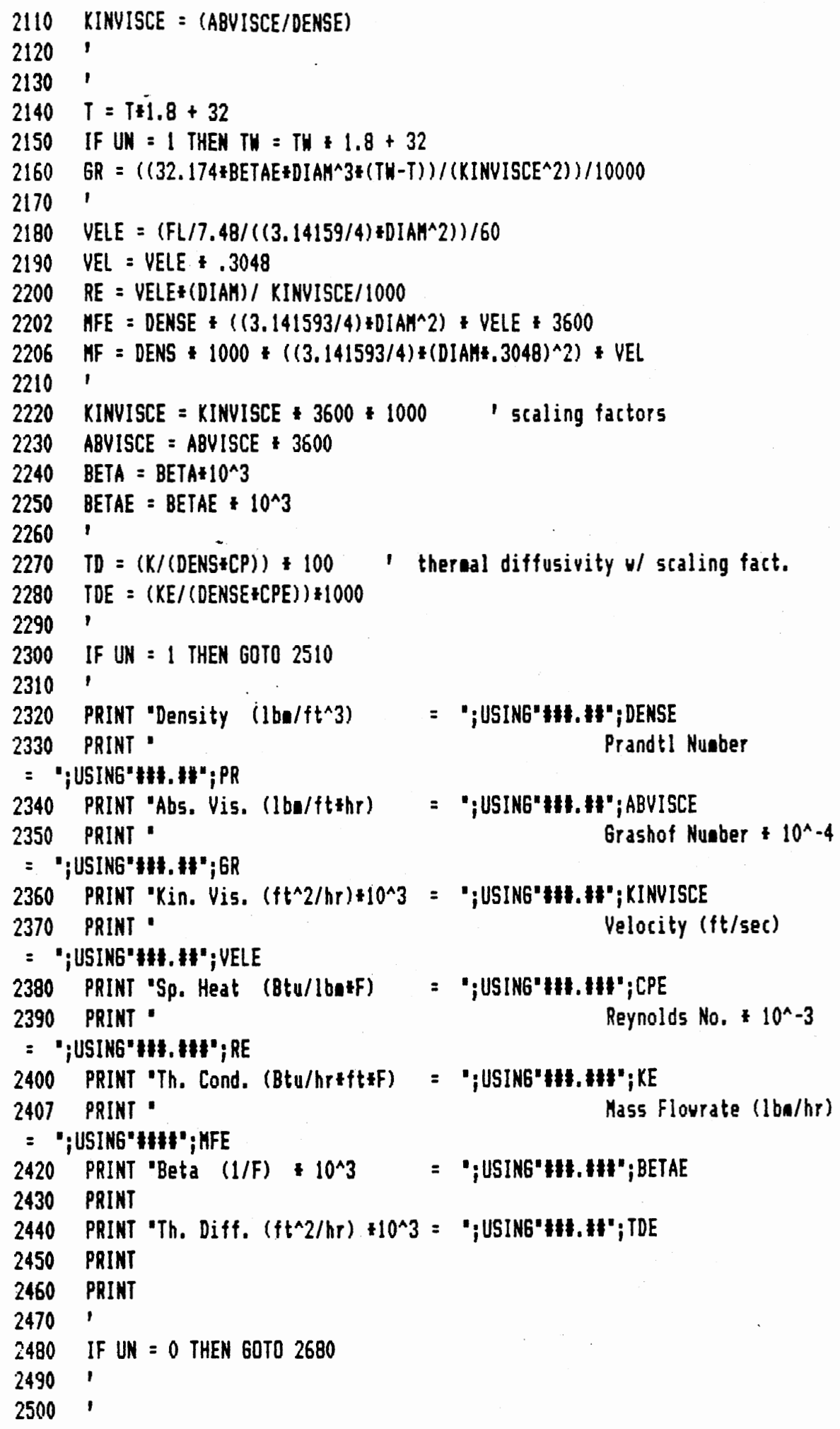




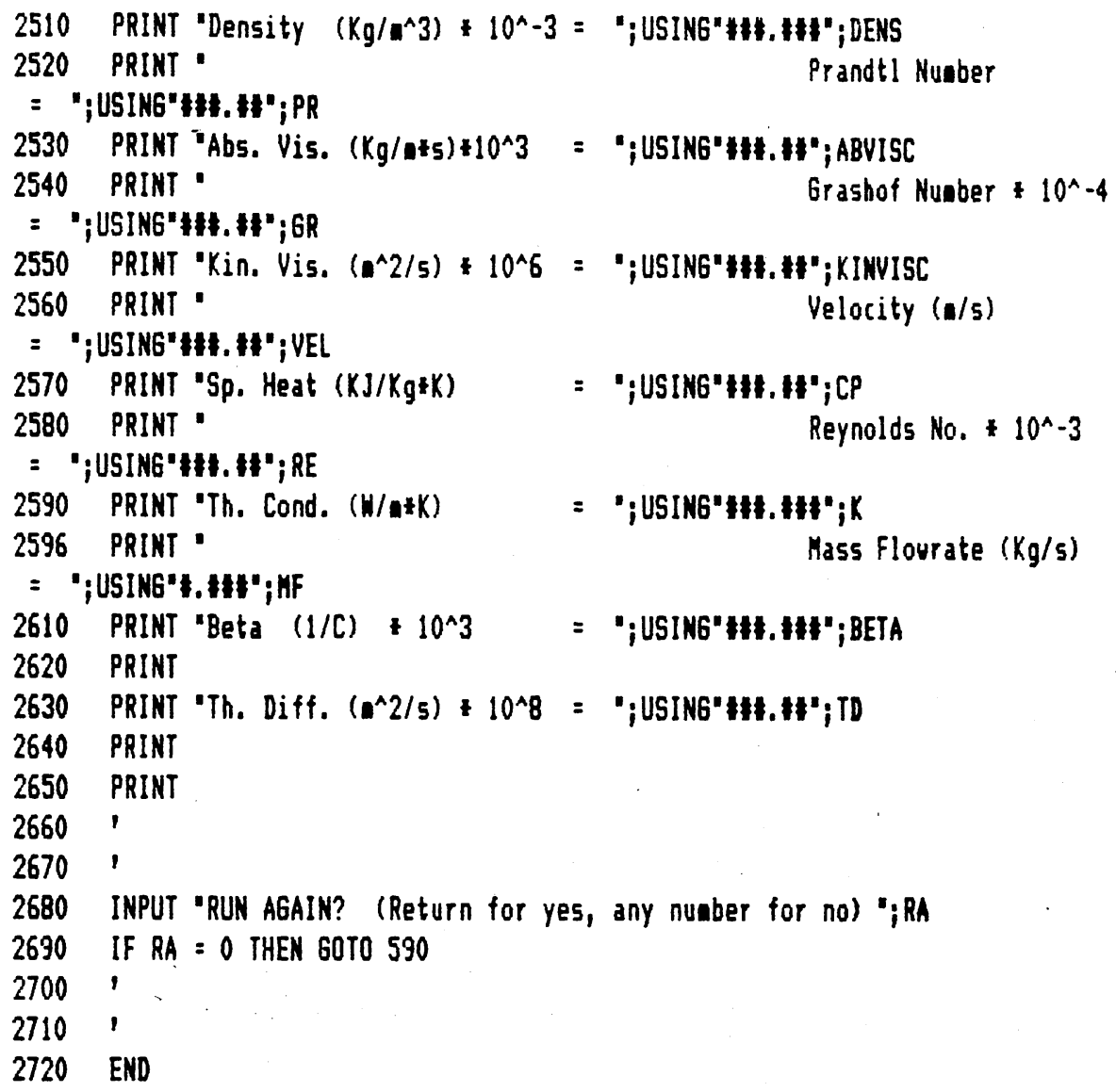




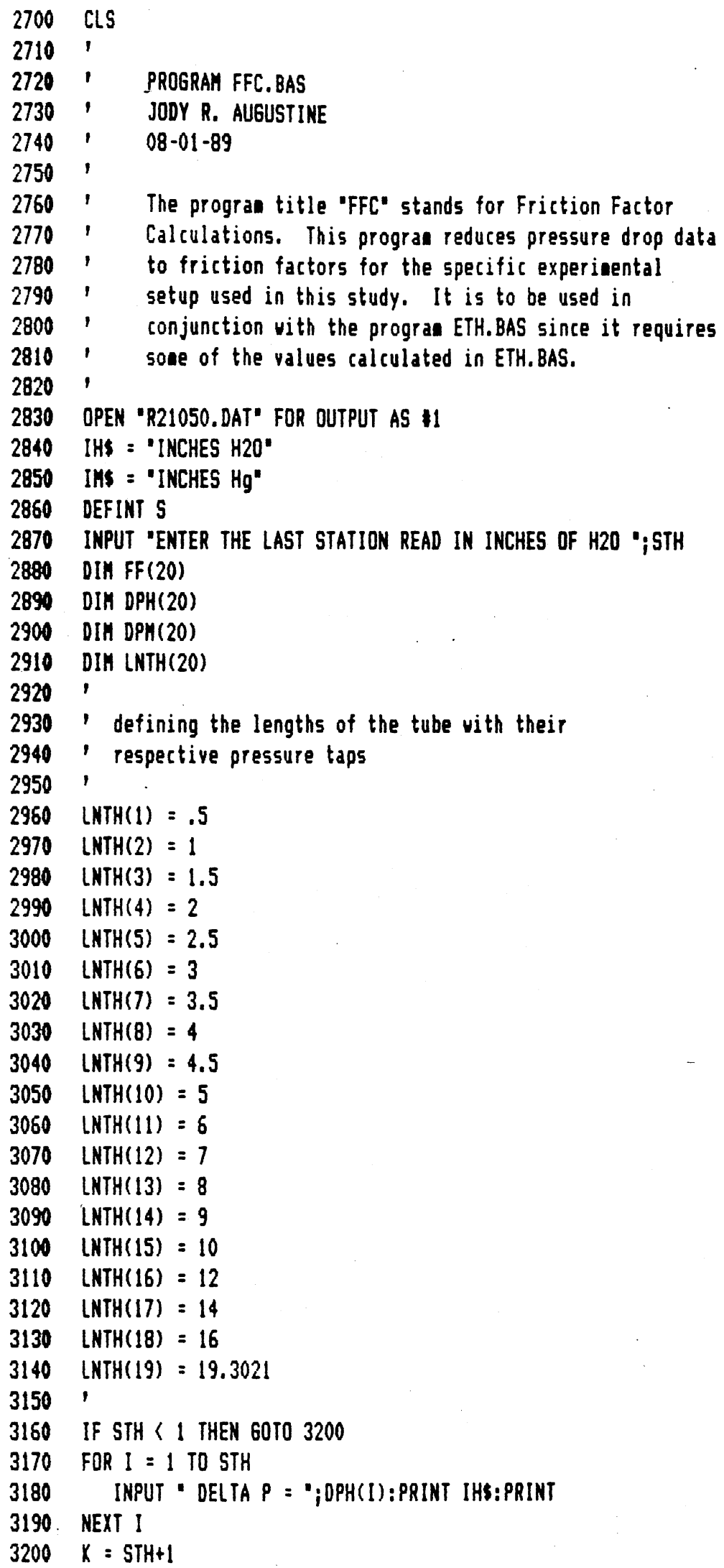




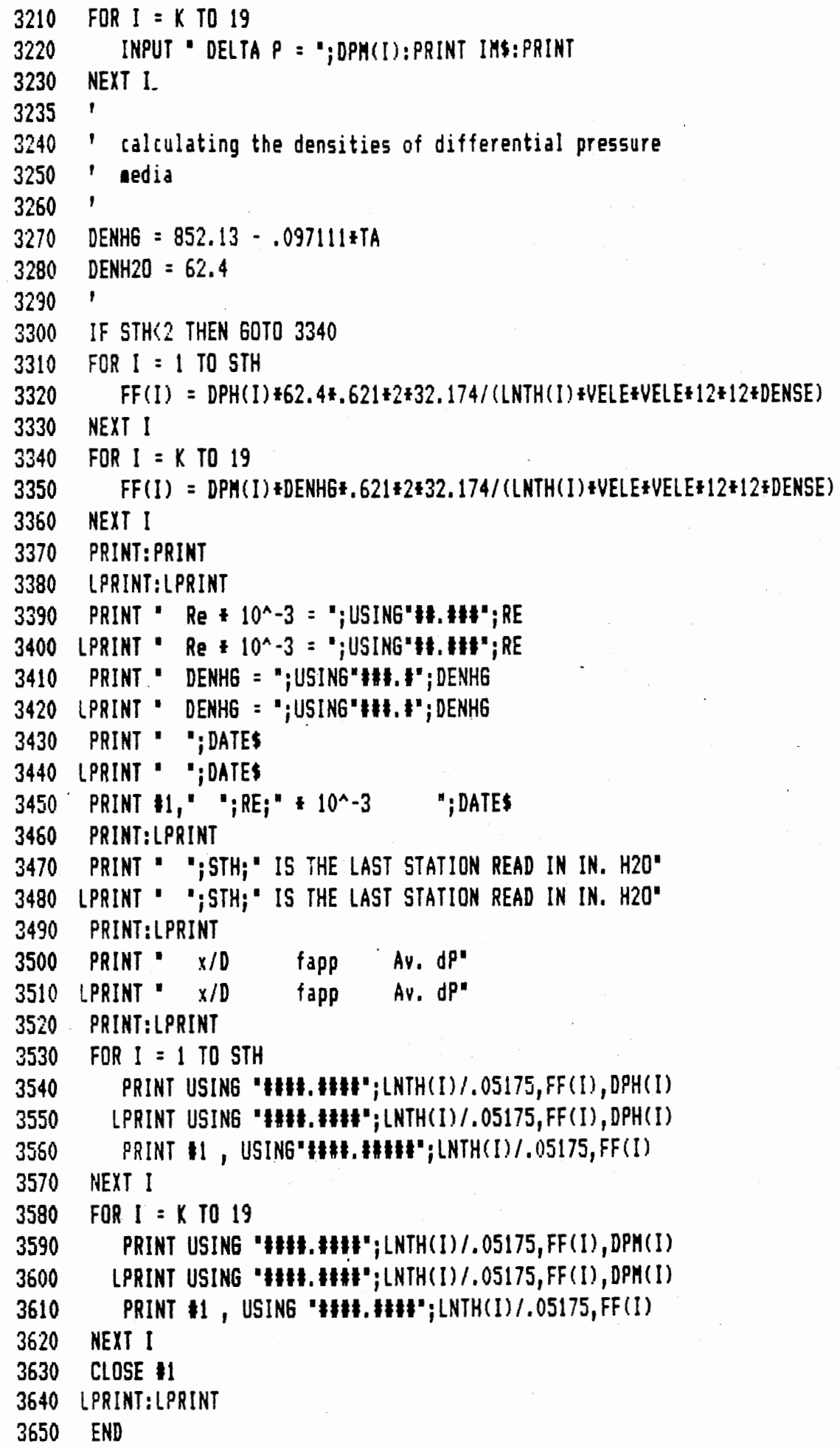







510 PRINT' the FlOMRATE INPUT IS NOT AVAILABLE FOR tHE SHALL METER'

520 PRINT

$53060 T 0900$.

540 PRINT" HHICH FLOMMETER DO YOU REQUIRE GPH DATA FOR? '

550 PRINT

560 INPUT' ENTER 'I' FOR SHALL METER, ENTER '2' FOR LARGE METER";A

570 PRINT

580 IF $A=1$ THEN CLS: 60TO 770

590 CLS

600 INPUT' ENTER THE FREQUENCY FOR THE LARGE TURBINEMETER';LF

610 IF LF〈55 GOTO 710

620 IF LF $>155$ 60T0 710

630 GPH=C1FLF+K1

640 CLS

650 PRINT

660 PRINT USING" FLOURATE = H. WH GPH"; GPM

670 PRINT

680 PRINT USING" FOR A FREQUENCY OF \$.IH HERTL";LF

690 GOTO 930

700 CLS

710 PRINT" THE FREQUENCY INPUT IS NOT IN tHE AVAILABLE LARGE METER RANGE'

720 PRINT

730 INPUT" DO YOU HISH TO TRY AGAIN (YES=1 NO=2) ; B

740 IF $B=2$ THEN CLS: GOTO 970

750 60TO 130

760 PRINT

770 INPUT' ENTER THE FREQUENCY FOR THE SMALL TURBINEMETER IN $\mathrm{Hz}^{\circ}$; SF

780 IF SF $<1356070870$

790 IF SF $>1080$ 60TO 870

800 GPH $=$ C $\$$ SF $+K$

810 CLS

820 PRINT

830 PRINT USING"

840 PRINT

850 PRINT USING" FOR A FREQUENCY OF HH. HW HERTL";SF

8606070930

870 CLS

880 PRINT" the FREQUENCY INPUT IS NOT AVAILABLE FOR THE SMALL METER'

890 PRINT

900 INPUT" DOU YOU HISH TO TRY AGAIN (YES=1 NO=2) ; $i$ BI

910 If $81=2$ THEN CLS: 60TO 970

320 60T0 130

930 PRINT

940 PRINT



360 If $l=1$ GOTO 130

970 END 


\section{APPENDIX E}

THERMOPHYSICAL PROPERTIES OF WATER AND ETHYLENE GLYCOL SOLUTIONS 
Physical Properties of Ethylene Glycol-Water Mixtures

The correlations for the physical properties were reported in ref. (1).

Density

$$
\rho=\sum_{i=1}^{3} \sum_{j=1}^{3} A_{i j} x^{(j-1)} T^{(i-1)}
$$

where

$$
\text { Values of } A_{i j}
$$

$\begin{array}{llll} & j=1 & j=2 & j=3 \\ i=1 & 1.0004 & 0.17659 & -0.049214 \\ i=2 & -1.2379 \times 10^{-4} & -9.9189 \times 10^{-4} & 4.1024 \times 10^{-4} \\ i=3 & -2.9837 \times 10^{-6} & 2.4614 \times 10^{-6} & -9.5278 \times 10^{-8}\end{array}$

$\rho=$ density, $\mathrm{g} / \mathrm{cm}^{3}$

$x=$ mass fraction of ethylene-glycol

$\mathrm{T}=$ temperature, ${ }^{\circ} \mathrm{C}$

This equation has an accuracy within $\pm 0.25 \%$. It is applied over the temperature range of 0 to $150^{\circ} \mathrm{C}$. 
Comparison of density correlation with other sources

$\begin{array}{lcl}\text { Pure Water } & -0.1 \% & \text { ref. (4) } \\ & 0 \% \text { to } 0.1 \% & \text { ref. (7) } \\ \text { Pure EG } & -1.0 \% \text { to }-0.2 \% & \text { ref. (6) } \\ 30 \% \text { EG } & -0.2 \% \text { to } 0.3 \% & \text { ref. (2) } \\ 50 \% \text { EG } & -0.2 \% \text { to } 0 \% & \text { ref. (2) } \\ 70 \% \text { EG } & -0.2 \% \text { to } 0.1 \% & \text { ref. (2) }\end{array}$

$\underline{\text { Viscosity }}$

$$
\ln \mu=\sum_{i=1}^{2} \sum_{j=1}^{3} A_{i j} x^{(j-1)} T^{(i-1)}+\left\{\sum_{j=1}^{3} A_{3 j} x^{(j-1)}\right\}^{1 / 4} T^{2}
$$

where

$$
\begin{array}{llcl} 
& \multicolumn{3}{c}{\text { Values of } A_{i j}} \\
& j=1 & j=2 & j=3 \\
i=1 & 0.5614 & 2.6492 & 0.82935 \\
i=2 & -2.7633 \times 10^{-2} & -3.1496 \times 10^{-2} & 4.8136 \times 10^{-3} \\
i=3 & 6.0629 \times 10^{-17} & 2.2389 \times 10^{-15} & 5.8790 \times 10^{-16}
\end{array}
$$

$\mu=$ viscosity, $\mathrm{mPa}-\mathrm{s}$

$x=$ mass fraction of ethylene glycol

$\mathrm{T}=$ temperature, ${ }^{\circ} \mathrm{C}$

This equation has an accuracy within $\pm 0.25 \%$. It is applied over the temperature range of 0 to $150^{\circ} \mathrm{C}$. 
Comparison of viscosity correlation with other sources

$\begin{array}{lll}\text { Pure water } & -7 \% \text { to } 3 \% & \text { ref. (4) } \\ & -12 \% \text { to } 10 \% & \text { ref. (7) } \\ \text { Pure EG } & -3.7 \% \text { to } 0.3 \% & \text { ref. (6) } \\ 30 \% \text { EG } & -10 \% \text { to } 5 \% & \text { ref. (2) } \\ 50 \% \text { EG } & -9 \% \text { to } 7 \% & \text { ref. (2) } \\ 70 \% \text { EG } & -4 \% \text { to } 0 \% & \text { ref. (2) }\end{array}$

\section{Thermal Conductivity}

$$
\begin{aligned}
& K_{W}=0.56276+1.874 \times 10^{-3} T-6.8 \times 10^{-6} T^{2} \\
& K_{E G}=0.24511+1.755 \times 10^{-4} T-8.52 \times 10^{-7} T^{2} \\
& K_{F}=0.6635-0.3698 \times-8.85 \times 10^{-4} T \\
& K_{M}=(1-x) K_{W}+x K_{E G}-K_{F}\left(K_{W}-K_{E G}\right)(1-x) x
\end{aligned}
$$

where

$K_{W}=$ thermal conductivity of pure water, $W / m-K$

$K_{E G}=$ thermal conductivity of pure ethylene glycol, W/m-K

$K_{F}=F i l i p p o v ' s$ constant

$K_{M}=$ thermal conductivity of ethelyne glycol-water mixture, $W / m-K$

$x=$ mass fraction of ethylene glycol

$\mathrm{T}=$ temperature, ${ }^{\circ} \mathrm{C}$

The equation has an accuracy within $\pm 1 \%$. It is applied over the temperature range of 0 to $150^{\circ} \mathrm{C}$. 
Comparison of thermal conductivity correlation with other sources

$\begin{array}{lll}\text { Pure water } & -0.3 \% \text { to } 0.3 \% & \text { ref. (4) } \\ & -0.7 \% \text { to } 0.1 \% & \text { ref. (7) } \\ \text { Pure EG } & -4.1 \% \text { to }-3.1 \% & \text { ref. (6) } \\ 30 \% \text { EG } & -4.6 \% \text { to } 0.3 \% & \text { ref. (2) } \\ 50 \% \text { EG } & -10 \% \text { to } 2 \% & \text { ref. (2) } \\ 70 \% \text { EG } & -11 \% \text { to } 6 \% & \text { ref. (2) }\end{array}$

Prandt7 Number

where

$$
\ln \operatorname{Pr}=\sum_{i=1}^{2} \sum_{j=1}^{3} A_{i j} x^{(j-1)} T^{(i-1)}+\left\{\sum_{j=1}^{3} A_{3 j} x^{(j-1)}\right\}^{1 / 4} T^{2}
$$

$$
\text { Values of } A_{i j}
$$

$\begin{array}{llll} & j=1 & j=2 & j=3 \\ i=1 & 2.5735 & 3.0411 & 0.60237 \\ i=2 & -3.1169 \times 10^{2} & -2.5424 \times 10^{-2} & 3.7454 \times 10^{-3} \\ i=3 & 1.1605 \times 10^{-16} & 2.5283 \times 10^{-15} & 2.3777 \times 10^{-17}\end{array}$

$$
\begin{aligned}
\operatorname{Pr} & =\operatorname{Prandt} 1 \text { number }, \mu \mathrm{C}_{\mathrm{p}} / \mathrm{K} \\
\mathrm{x} & =\text { mass fraction of ethylene glycol } \\
T & =\text { temperature },{ }^{\circ} \mathrm{C}
\end{aligned}
$$

This equation has an accuracy within $\pm 5 \%$. It is applied over the temperature range of 0 to $150^{\circ} \mathrm{C}$. 
Comparison of Prandt 1 Number correlation with other sources

$\begin{array}{lll}\text { Pure Water } & -5 \% \text { to } 2 \% & \text { ref. (4) } \\ & -15 \% \text { to } 10 \% & \text { ref. (7) } \\ \text { Pure EG } & -5 \% \text { to } 4 \% & \text { ref. (6) }\end{array}$

Coefficient of Thermal Expansion

$$
\begin{aligned}
\beta=-(1 / \rho)\{ & -1.2379 \times 10^{-4}-9.9189 \times 10^{-4} \times+4.1024 \times 10^{-4} x^{2} \\
& \left.+2\left(-2.9837 \times 10^{-6} \mathrm{~T}+2.4614 \times 10^{-6} \times \mathrm{T}-9.5278 \times 10^{-8} \mathrm{x}^{2} \mathrm{~T}\right)\right\}
\end{aligned}
$$

where

$$
\begin{aligned}
& \beta=\text { coefficient of thermal expansion, } 1 /{ }^{\circ} \mathrm{C} \\
& \rho=\text { density }, \mathrm{g} / \mathrm{cm}^{3} \\
& x=\text { mass fraction of ethylene glycol } \\
& T=\text { temperature },{ }^{\circ} \mathrm{C}
\end{aligned}
$$

This equation was derived from the relation $\beta=(1 / \rho)(\partial \rho / \partial T)_{p}$, with the use of the density correlation listed previously. It is applied over the temperature range of 0 to $150^{\circ} \mathrm{C}$.

Comparison of $\beta$ correlation with other sources

Pure Water

Pure EG

$$
-18 \% \text { to }-3 \%
$$$$
5 \% \text { to } 8 \%
$$

ref. (3)

ref. (5) 
Comparison of secondary properties (properties that were calculated from the listed correlations) with other sources.

Kinematic Viscosity

$$
\begin{aligned}
& \nu=\text { Kinematic viscosity, } \mathrm{m}^{2} / \mathrm{s} \\
& \nu=\mu / \rho
\end{aligned}
$$

Pure Water

$-7 \%$ to $3 \%$

ref. (4)

Pure EG

$-3 \%$ to $1 \%$

ref. (6)

Specific Heat

$$
\begin{aligned}
& C_{p}=\text { specific heat, } \mathrm{J} / \mathrm{kg}-\mathrm{K} \\
& C_{p}=\operatorname{PrK} / \mu
\end{aligned}
$$

$\begin{array}{lll}\text { Pure Water } & 0.3 \% \text { to } 1.2 \% & \text { ref. (4) } \\ & -0.7 \% \text { to } 0.6 \% & \text { ref. (7) } \\ \text { Pure EG } & -4 \% & \text { ref. (6) } \\ 30 \% \text { EG } & -5 \% \text { to }-3 \% & \text { ref. (2) } \\ 50 \% \text { EG } & -2 \% \text { to } 2 \% & \text { ref. (2) } \\ 70 \% \text { EG } & -1 \% \text { to } 0 \% & \text { ref. (2) }\end{array}$

Thermal Diffusivity

$$
\begin{aligned}
& \alpha=\text { thermal diffusivity, } \mathrm{m}^{2} / \mathrm{s} \\
& \alpha=K / \rho C_{p}
\end{aligned}
$$

Pure EG

$1 \%$ to $1.5 \%$

ref. (6) 


\section{References}

1. Bohn, D., Fischer, S., and Obermeir, E. "Thermal Conductivity, Density, Viscosity and Prandt1 Numbers of Ethylene Glycol-Water Mixtures" Ber. Bunsenges. Phys. Chem. Vol. 88, pp. 739-742 (1984)

2. Glycols, Union Carbide Chemicals Co., New York (1985).

3. Heat Exchanger Design Handbook, Hemisphere Publishing Corp. (1983).

4. Kays, W.M., and Crawford, M.E., Convective Heat and Mass Transfer, McGraw Hi11, New York (1980).

5. Moshfeghian, M., Fluid Flow and Heat Transfer in U-Tube Bends, Ph.D. Thesis, Oklahoma State University, Stillwater, OK (1978).

6. White, Frank M., Heat and Mass Transfer, Addison Wes ley, New York (1988)

7. Zografos, A.I., Martin, W.A., and Sunderland, J.E., "Equations of Properties as a Function of Temperature for Seven Fluids", Computer Methods in Applied Mechanics and Engineering, v. 61, pp. $177-187$ (1987). 


\title{
VITA
}

\author{
Jody R. Augustine \\ Candidate for the Degree of \\ Master of Science
}

Thesis: PRESSURE DROR MEASUREMENTS IN THE TRANSITION REGION FOR A CIRCULAR TUBE WITH A SQUARE-EDGED ENTRANCE

Major Field: Mechanical Engineering

Biographical:

Personal Data: Born in Mckinney, Texas, June 3, 1965, the son of Roy $C$. and Connie Augustine.

Education: Graduated from Holy Savior Menard Central High School, Alexandria, Louisiana, in May, 1983; received Bachelor of Science Degree in Mechanical Engineering from The University of Southwestern Louisiana in May, 1988; completed requirements for the Master of Science Degree at oklahoma state University in May, 1990.

Professional Experience: Teaching Assistant, Department of Mechanical \& Aerospace Engineering, Oklahoma state University, August, 1988, to December, 1989. Research Assistant, Department of Mechanical \& Aerospace Engineering, Oklahoma state University, January, 1989, to December, 1989. 